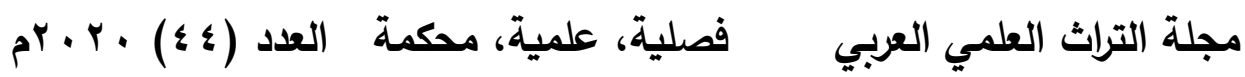

\section{أنساق المثاقفة التراثية في مجهوعة "روحه البحر والريح" ليونس البوسعيدي}

$$
\text { د.رسول بلاوي }
$$

(أستاذ مشارك، قسم اللغة العربية وآدابها في جامعة خليج فارس، بوشهر - ايران)

r.ballawy@pgu.ac.ir

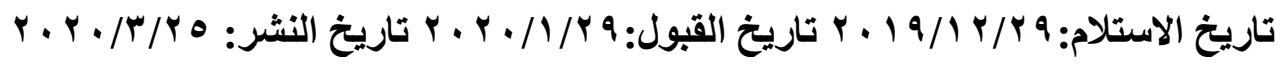

تُعدّ المثاقفة التراثية من أبرز الظواهر التي انتثرت في الثعر العربي قديمه وحديثه،

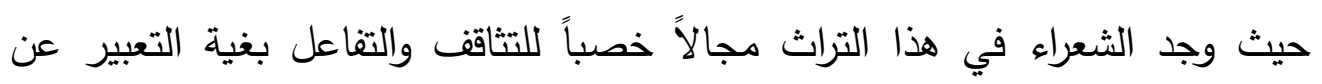
فكرتهم ورؤيتهم. والثاعر يونس البوسعيدي من الثعراء الذين أحسنوا توظيف التراث

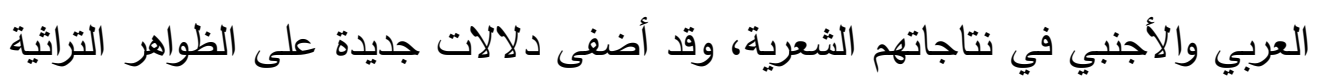

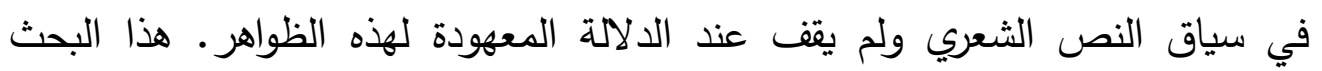

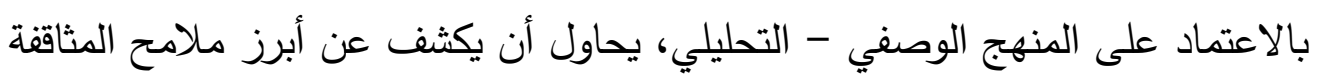

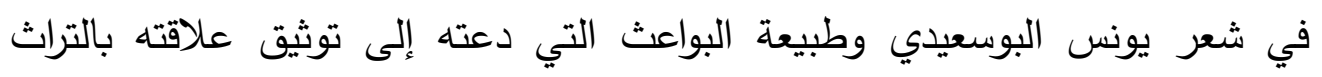

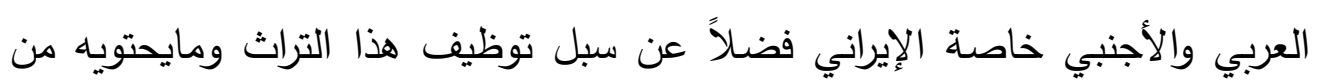
معانٍ ودلالات.

الكلمات المفتاحية: الثعر العُماني المعاصر، المثاقفة، التراث، يونس البوسعيدي، مجموعة "روحُهُ البحرُ والرّبح".

The types of acculturation in Yones Alboosaeedi's book" His soul is the sea and the wind"

Dr.Rasoul ballawy

(Associate Professor, Persian Gulf University, Bushehr - Iran)

\section{Abstract:}

Abstract traditional acculturation is one of the significant phenomena which is used in the old and modern arabic poetry. Poets have found in this tradition and flourishing arena for acculturation and interaction to Express their thoughts and inspection. Yones Alboosaeedi is one of the poets who 


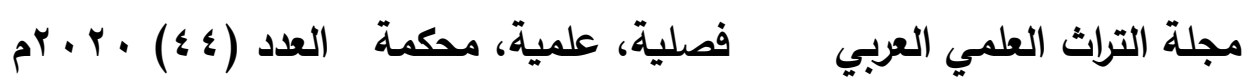

acted well using the arabic and foreign traditions in his works. He explained new concepts besides those traditional ones in the poetry text and he went beyond its conventional concepts .

This descriptive analytical resesrch tries to find the most important signs of acculturation in Alboosaeedi's poetry and the expeditions which call him to approve his relations to Arabic and foreign traditions especially iranian tradition besides the ways of hiring this tradition and all its meanings and implications .

Keywords: modern Omani poetry, acculturation, tradition, tones Alboosaeedi, His soul is the sea and the wind.

عكف الثعراء على التراث ليستمدّوا من مصادره المختلفة كالموروثات الدينية، والتاريخية، والأدبية والصوفية، والأسطورية والفولكلورية، عناصر ومعطيات مختلفة،

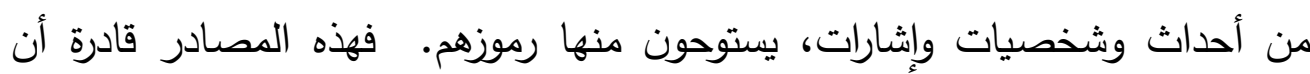
ترفد النص بطاقات ودلالات فاعلة؛ فالثاعر يجد عبرها طريقاً أقصر لنقل المفاهيم إلى المتلقي الذي يرتاح ويستأنس لهذا التراث. والثاعر العماني يونس البوسعيدي أدرك مدى طاقات هذا التراث لنقل فكرته إلى مخاطبه فأقبل عليه يستمدّ منه آلياته التعبيرية. تثاقف الثاعر يونس البوسعيدي في مجموعته الموسومة بـ "روحُهُ البحرُ والرّّح" مع

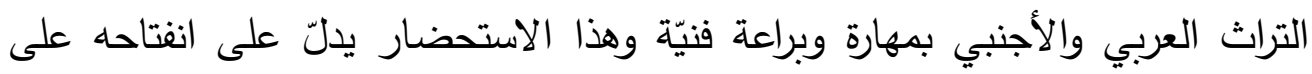

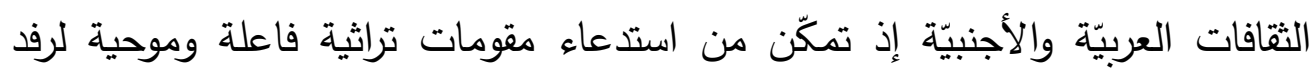
نصوصه بدلالات ومعانٍ تشدّ المتلقّي نحوها. استدعى في نتاجاته الشعريّة نصوصاً

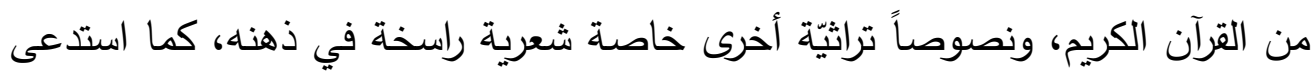

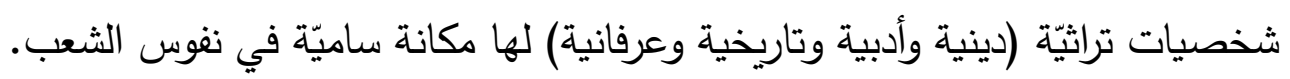
تُعدّ المثاقفة مع المعطيات التراثية سمة بارزة في شعر البوسعيدي خاصة في ديوانه الموسوم بـ روحُهُ البحرُ والرّيّح"، وهي تثير إشارة جلية إلى عميق قراءته للتراث، وقدرته بـه 


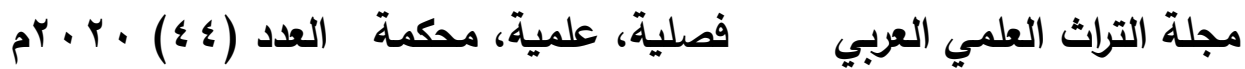

على استغلال عناصره ومعطياته التي من شأنها أن تمنح النص فضاءً شعريًاً واسعاً

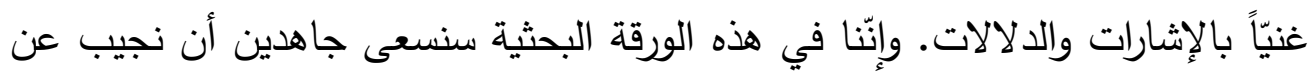

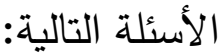

- كيف تجلّت المثاقفة التراثية في مجموعة "روحُهُ البحرُ والرّيح" ليونس البوسعيدي؟ - ما هي أبرز دلالات المثاقفة التراثية في شعر البوسعة روخيدي وما مدى فاعليتها في النص؟

- وما هو أثر هذا التثاقف التراثي على مخيلة المتلقي؟

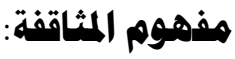

المثاقفة هي التحاور بين ثقافة أصلية لدى الثخص وبين ثقافة مستحدثة يقبل عليها

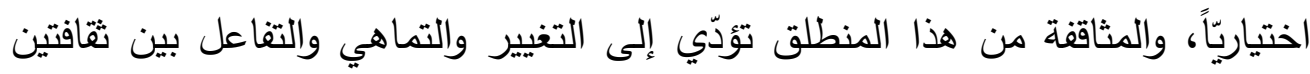
وليس خضوع ثثافة لأخرى (1). تركيب المفردة اللغوي يوحي بمعانٍ عدّة أهمّها التلاقي، والاحتكاك، والتمازج، والتبادل والتفاعل، والتواصل، ويعبّر عن ميل الإنسان

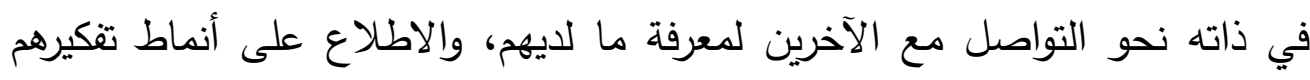
وأساليب حياتهم (r).

في عملية المثاقفة يكتسب الثخص أو الجماعة خصائص ثقافية أخرى تمكّنه من التواصل والتفاعل مع الآخرين كما تمكّنه من التعبير عن رؤية بعمق ثم تؤدّي إلى الثى

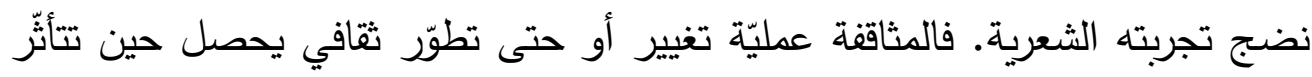

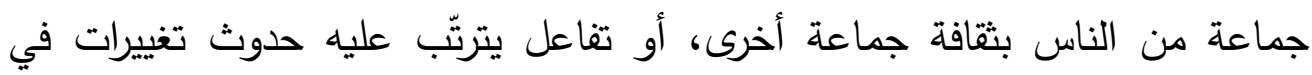

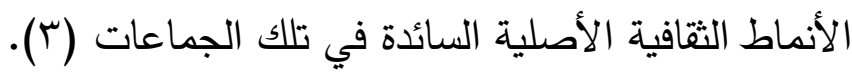

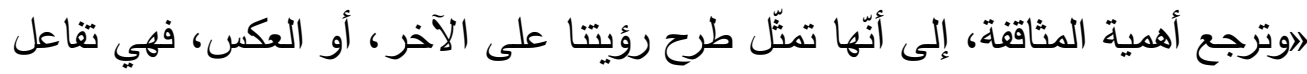

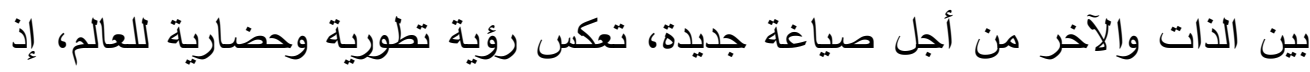

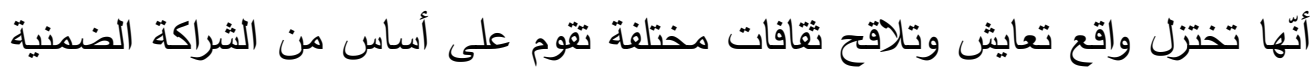
بين (الأنا) و (الآخر) بغية إنتاج معرفة موضعية، تهدف إلى الارتقاء بالإنسان

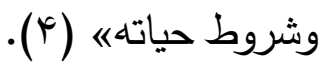




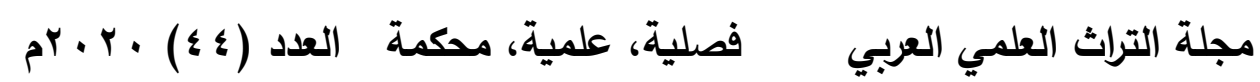

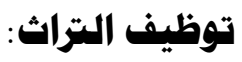

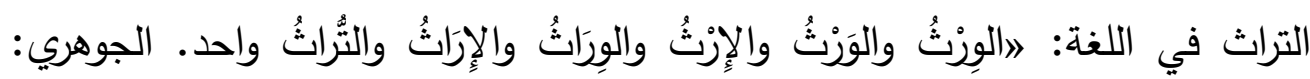

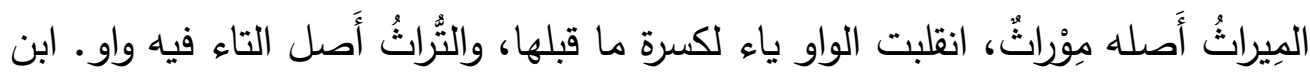

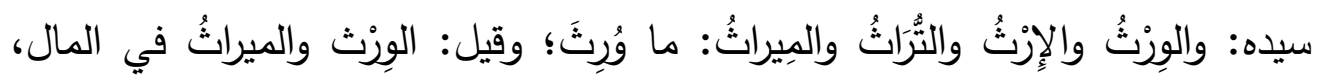

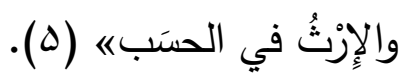

وقد وردت كلمة 》التراثه في القرآن الكريم مرّة واحدة بمعنى ما يُورَّث أو تَركِكة الميِّّ

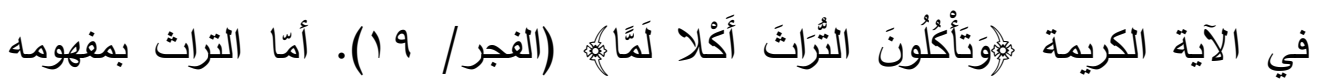

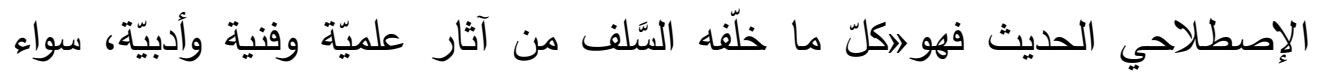

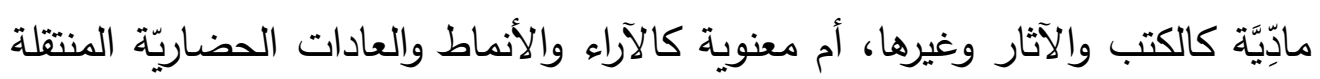

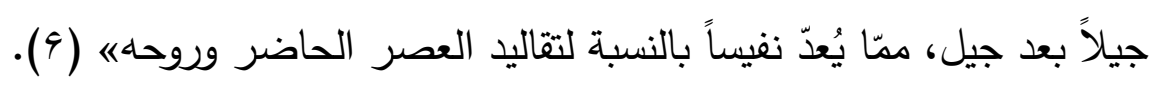

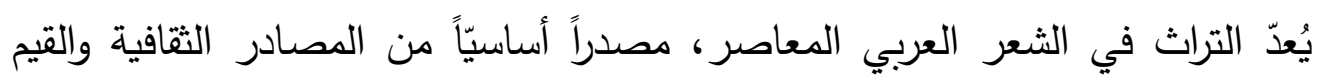

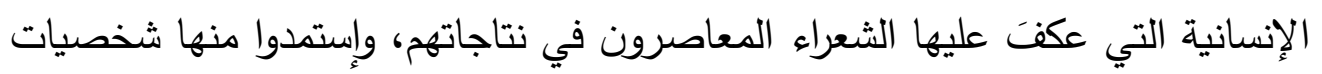

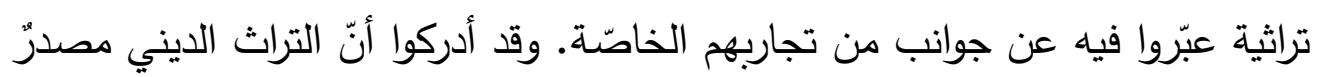

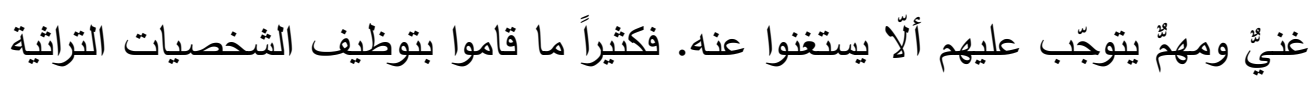

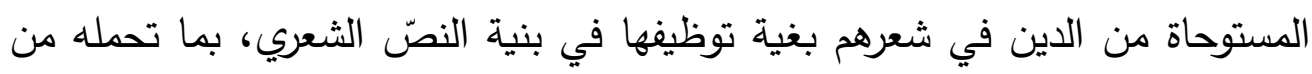

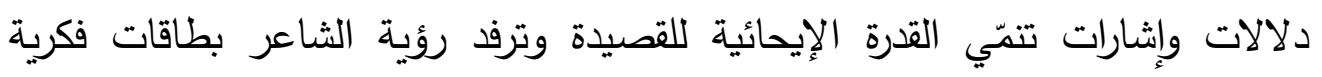
مفتوحة على التأويل (V).

في العصر الحديث يدوّن الثاعر المعطيات التراثية ويعبّر عنها، إذ أصبح

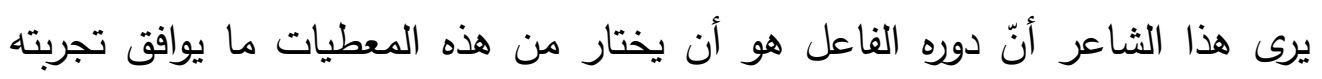

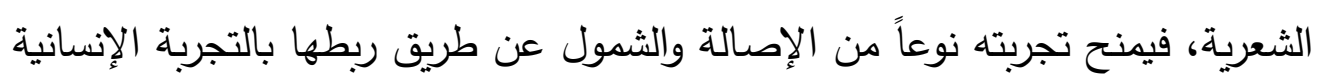

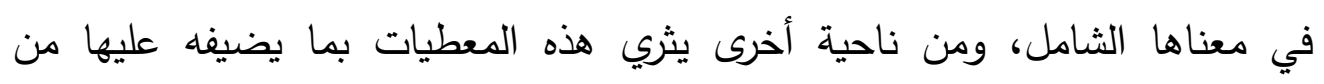

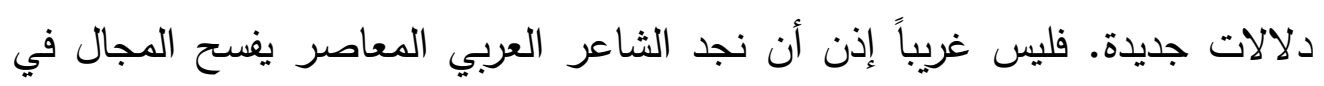

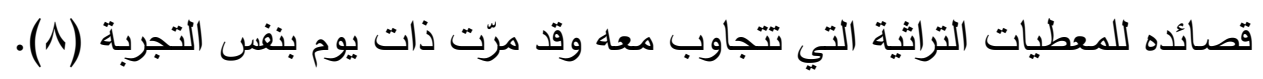




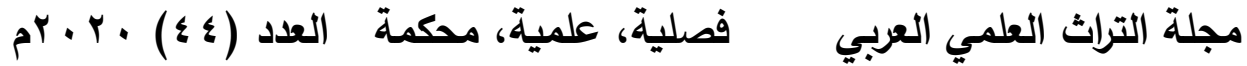

يختار الثاعر من الشخصيات ما يوافق طبيعة أفكاره وهمومه التي يريد أن

ينقلها إلى المتلقي. طبيعة المرحلة التاريخية والحضارية التي عاشتها الأمة العربية في

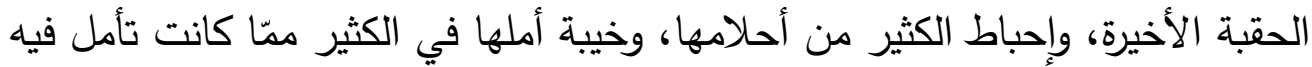
الخير، وسيطرة بعض القوى الجائرة على بعض مقدراتها، والهزائم المتكررة التي حاقت بها رغم عدالة قضيتها، انعكس كل ذلك على نوعية الثخصيات التاريخية التي استمدها الثاعر المعاصر (9).

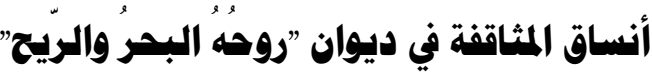

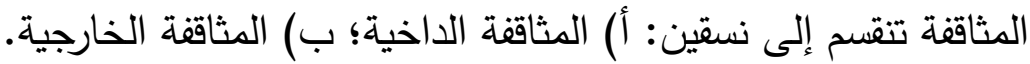
أ) المثاقفة الداخلية

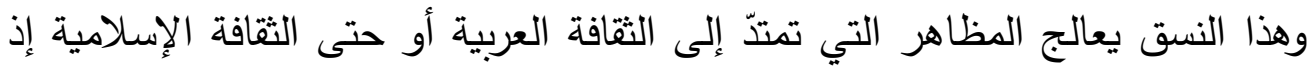

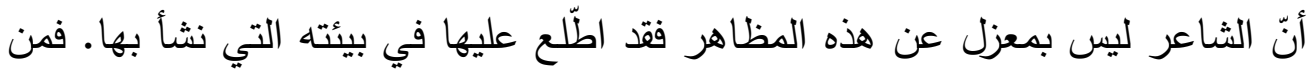
أبرز مظاهر المثاقفة الداخلية هي، أوّلاً: المثاققة النصيّة (القرآن الكريم والثعر العربي)؛ ثانيّاً: مثاقفة استدعاء الثخصيات التراثية الثراثية (الدينيّة، والأدبية، والتاريخية،

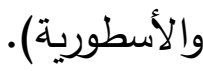

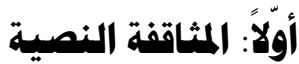

تتقسم المثاقفة النصيّة في ديوان "روحُهُ البحرُ والريح" على قسمين: المثاقفة القرآنية والمثاقفة الثعرية. وفي ما يأتي ندرسُ كلّ منهما:

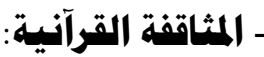

التعالق مع النص القرآني في الثعر الحديث يدلّ على ثقافة شمولية عامّة، وظفّها

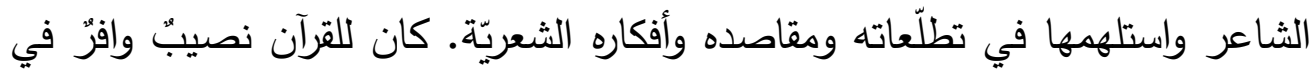
النصوص الشعرية فالقرآن معين لا ينضب، وقد ألهمّ الشعراء والكتّاب والمتطلّعين إلى الثى

$$
\text { الحريّة والخلاص عبر العصور (· ( ). }
$$

أقبل الثاعر المعاصر على القرآن الكريم وأخذ ايستدعيه بوصفه جزءاً من البنية الدلالية للنصّ الثعري، فالإثارات القرآنية ترتبط مع النص الثعرد الثعري عضوياً وبنيوياً 


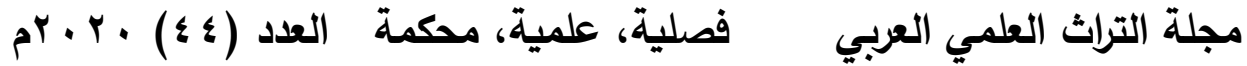

ودلالياً، وهذا تتويع جديد على الموقف نفسه ويؤكّد أنّ العملية ليست مجرد عملية أقتباس، وإنّما هي عملية تفجّر لطاقات كامنة في النصّ يستكثفها شاعر بعد آخر ، وكل حسب موقفه الشعري الراهنه (1). والثناعر يونس البوسعيدي وجدَ في القرآن

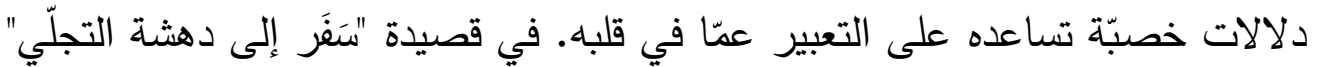

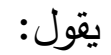

في دهثتي العذراء يا أمتي الولد

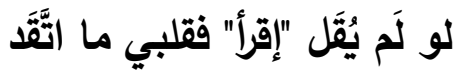

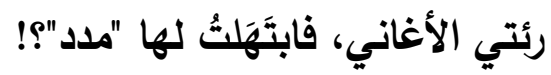

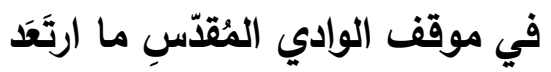

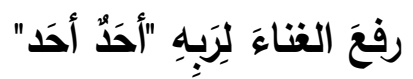

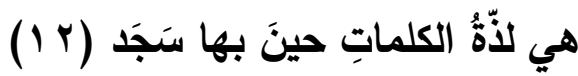

أنا ذلكم في الغار أمّي، فأحضُني ..

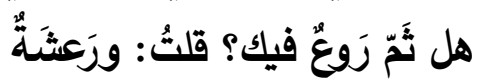

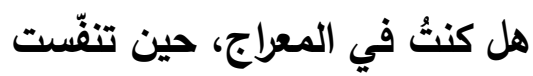

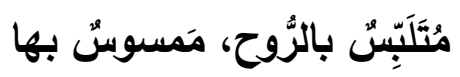

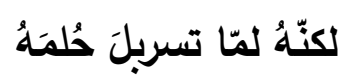

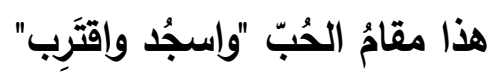

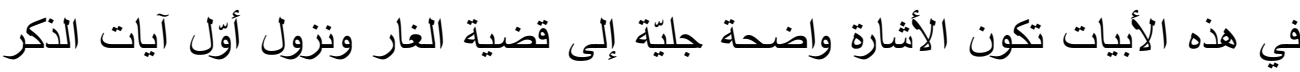
الحكيم على قلب النبيّ الأمي العببي. جاءت البدارة البداية (أنا ذلكم في الغار أمّي) تمهيداً

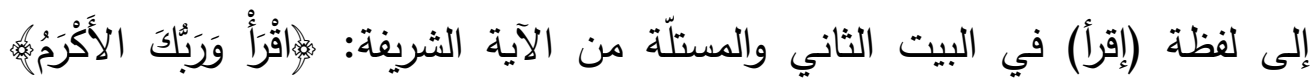

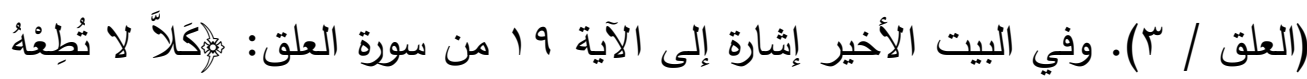

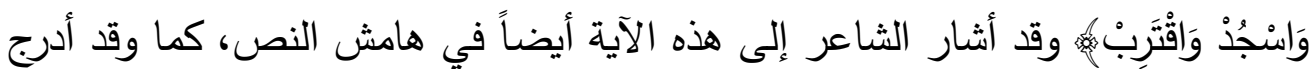
العبارة في علامة التصيص داخل القصيدة. وفي البيت الرابع إثارة إلى الآية الكريمة:

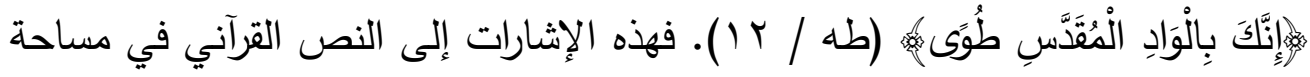
قصيرة من القصيدة تدلّ على انفتاح الثاعر على مفاهيم القرآن وقدرته الفنيّة في استخدام ما يناسب فكرته من النص القرآني الثريف. وفي قصيدة تحمل عنوان "هديل على سدرة الكنتهى" يقول البوسعيدي: تحتها، والصلاًة تثهُ كفرَه المُعنّى كعابٍِ النارِ يحنو تهنو

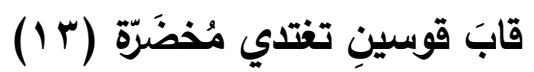

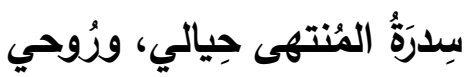




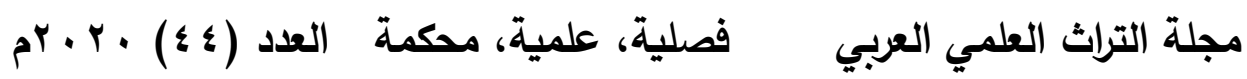

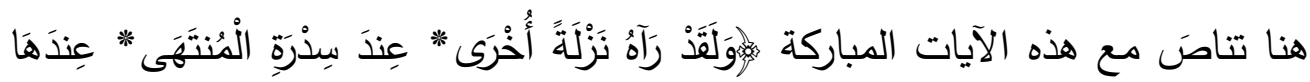

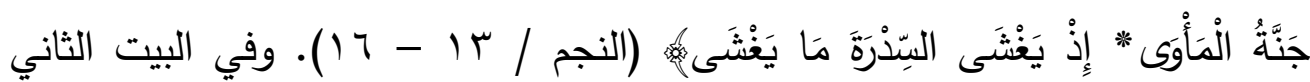

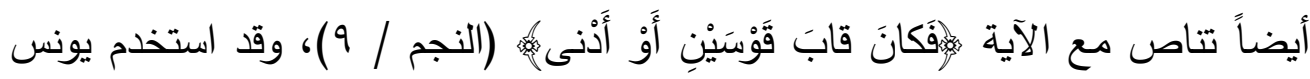

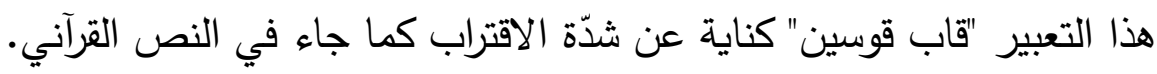

كي أرى الرُوحَ أنّها؛ إنَّها الأُمنيّة

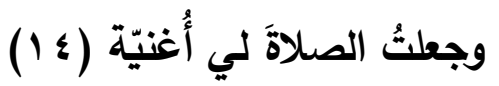

وفي قصيدة "ولكن ليطَئنّ قَلبي" يقول يونس:

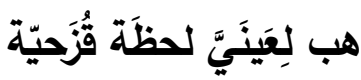

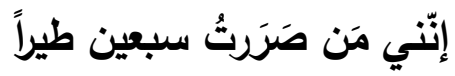

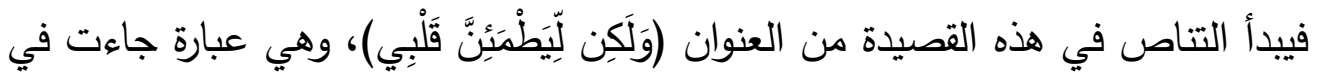

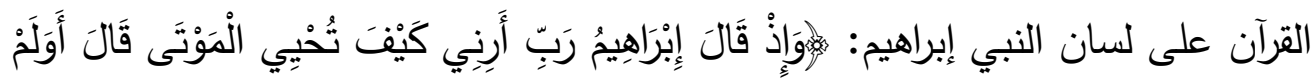

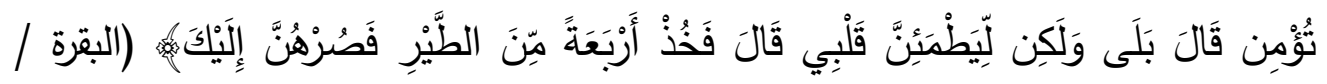

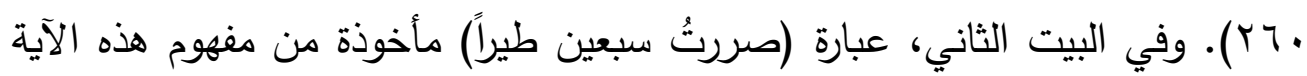

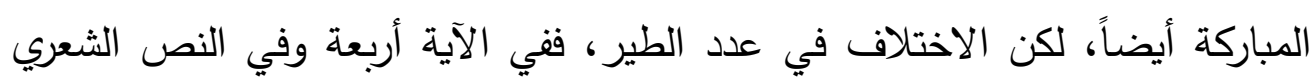

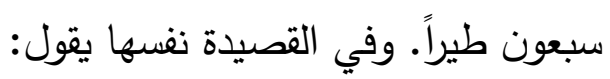

قانطُ قانتُ كما الأُضحيَّة

و "إذا الثمسُ كوِّرَت" مَتليّة

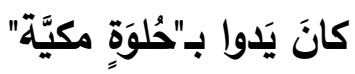

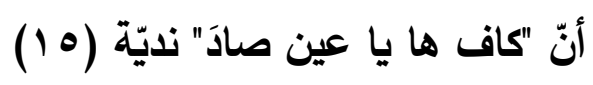

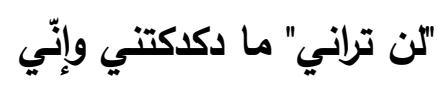

يا .... وياا... ياا....، كان الغُبارُ مُضيئاً

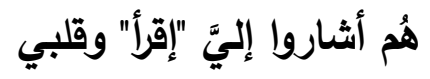

قَرََفَاً ما حسوتُهُ سُكَّرِيًاً

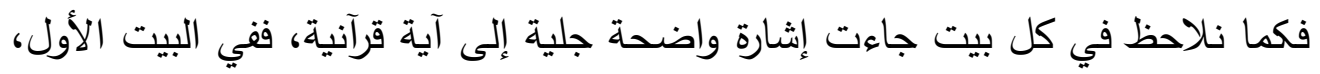

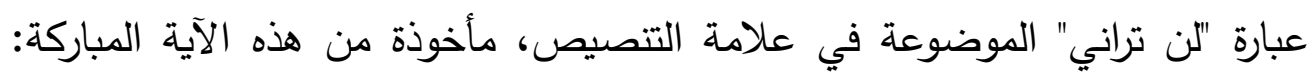

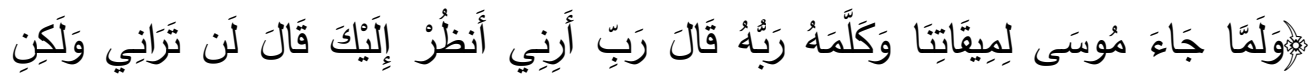

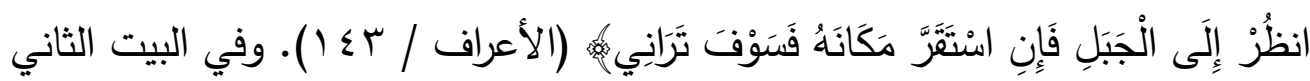

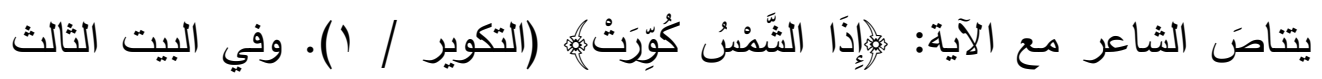

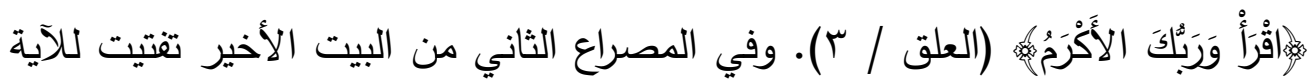

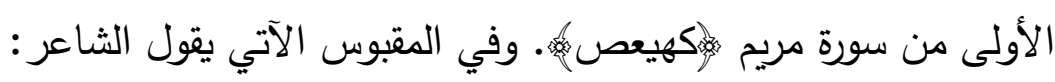




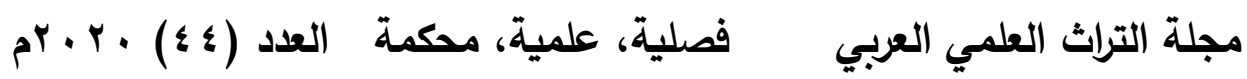

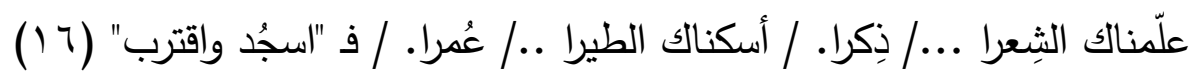

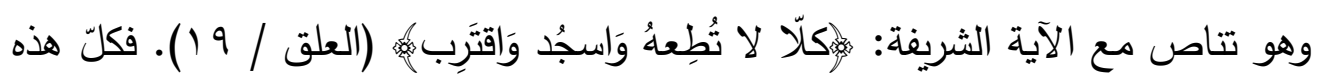
الثواهد تدلّ بوضوح على مدى التعالق بين نصوص الثاعر والنص القرآني المبارك.

\section{- المثاقفة الشعرية:}

وفي إطار سعي الثاعر يونس البوسعيدي للتعبير عن أفكاره تعبيراً موفقاً اهتدى إلى هنى

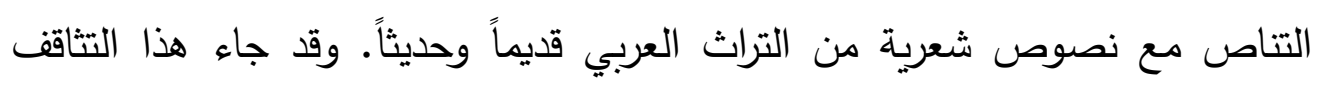

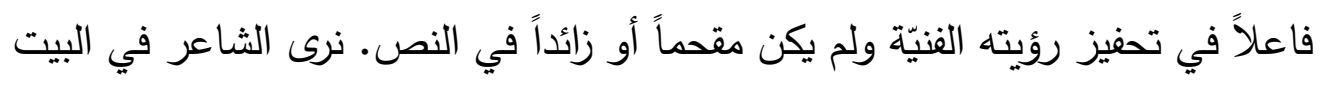

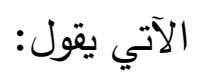

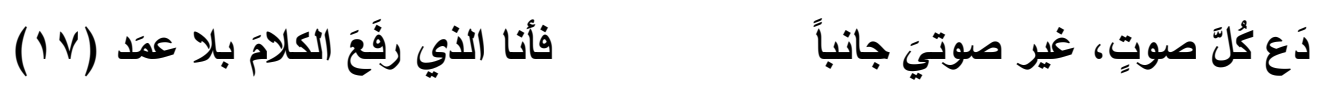

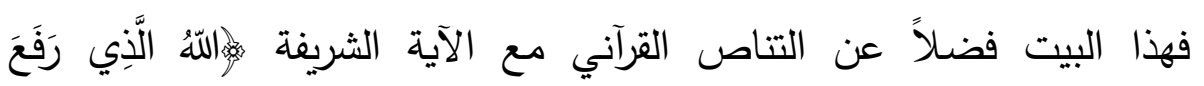

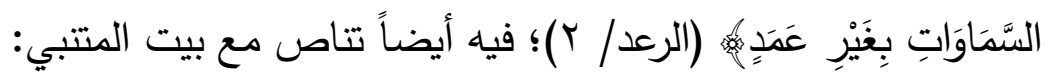

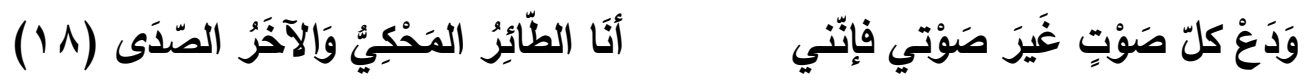

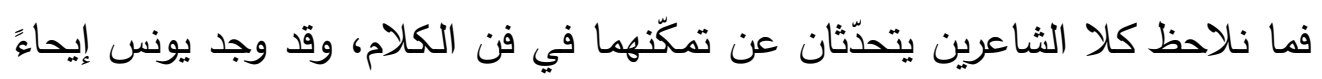

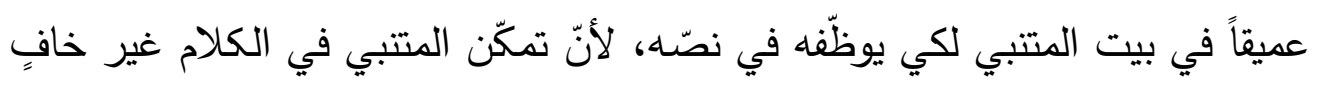
على المتلقي. وفي نصّ آخر يقول البوسعيدي:

حيثُ الصحافةُ في تبريجها القَشِبِب

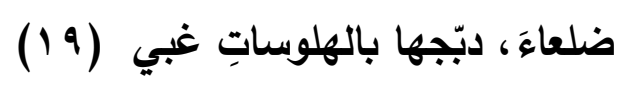

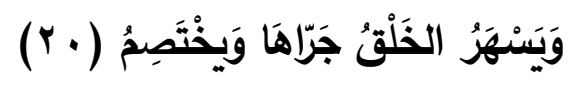

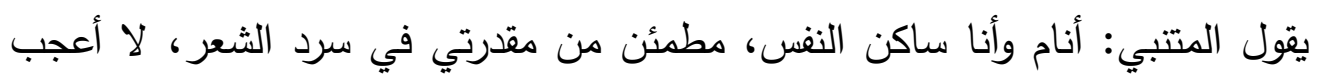

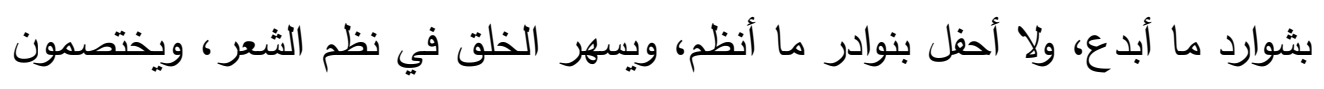

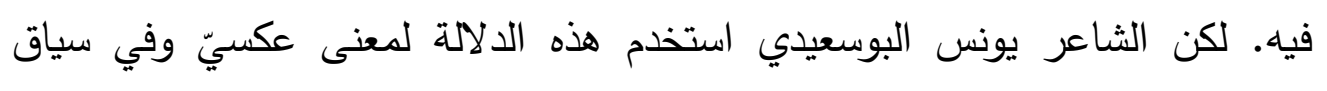

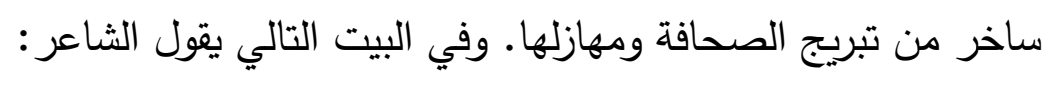

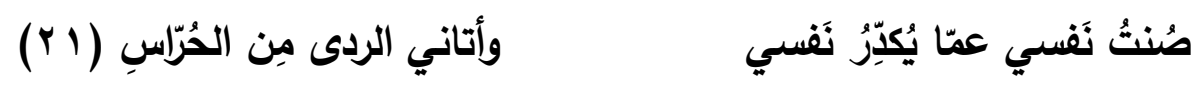

أنامُ مله جفوني عن مهازِّها

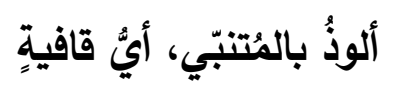

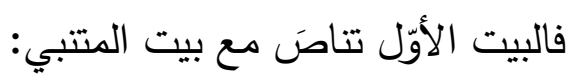

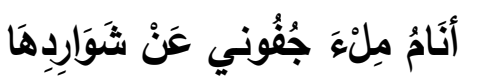




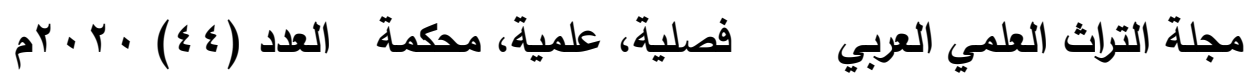

\section{وهو تناصُّ واضحِّ مع بيت البحتري:}

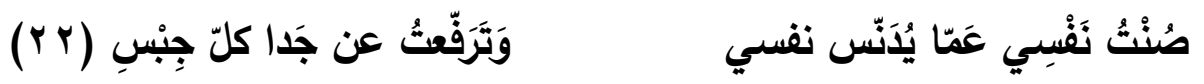

فقد قام يونس بتغيير لفظة (يُدَنّس) بمفردة (يُكِّرُ) كما يتطلبه سياق النصّ. وفي البيت الآتي يقول البوسعيدي: أَتَرُّرُ من فوقي الصراطِ مغامراً

المصراع الثاني مستلّ من قصيدة "في البيت أجلُسُ" لمحمود درويش والتي جاء فيها:

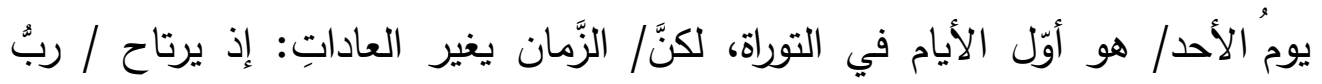

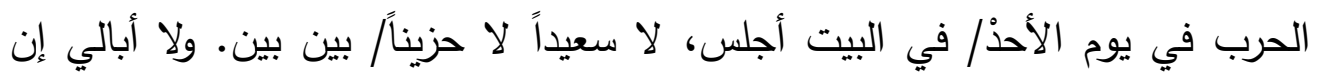

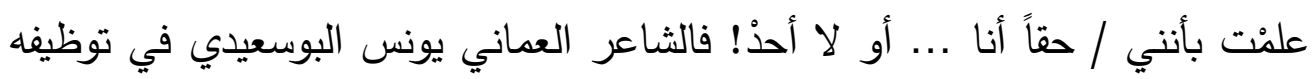
لهذه النصوص الثعرية من التراث العربي ربطَ تجربته بمعين دلالي خصب يساعده لهاه على نقل رؤاه إلى المتلقي بسرعة، لأنّ هذه النصوص وكذلك شعراءها تتمتِّع بمقبوليّة لاى الوسط الثقافي.

\section{ثانيًّ: استدعاء الشخصيات التراثية:}

استدعاء الثخصيات التراثية يُعدُّ من أبرز التقنيات التي اعتمدها الثاعر في قصائده،

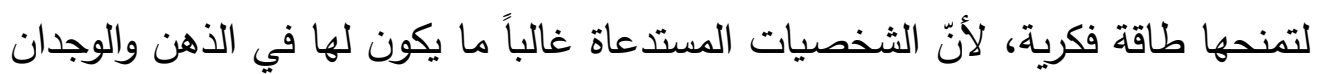

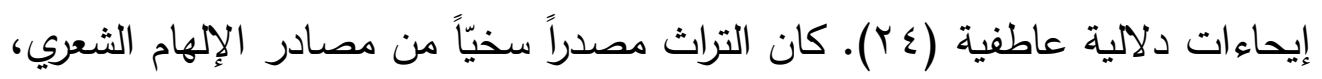

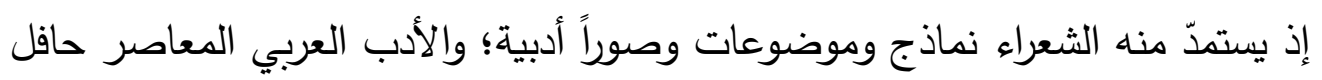
بالكثير من الأعمال الأدبية العظيمة التي محورها شخصية تراثية. فلهذا يعدّ التراث في الأدب العربي المعاصر، مصدراً أساسيّاً من المصادر الثقافية والقيم الإنسانية التي لإني عكف عليها الثعراء المعاصرون، واستمدوا منها شخصيات تراثية عبّروا فيها عن الإسيه جوانب من تجاربهم الخاصة.

"إنّ التراث مصدر غني وهامّ يتوجّب عليهم أن لا يستغنوا عنه. فكثيراً ما قاموا

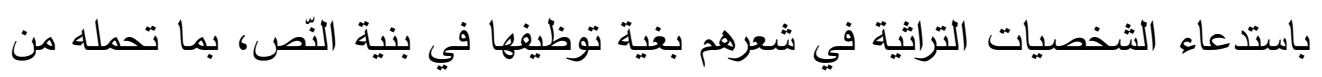

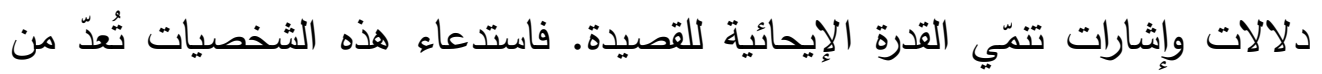




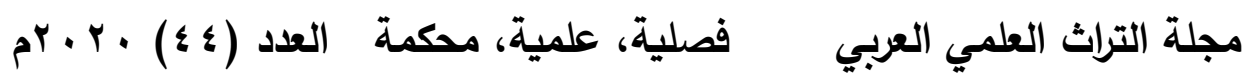

أبرز التقنيات التي أعتمدها الشعراء في قصائدهم لتمنحهم حمولة فكرية ووجدانية

$$
\text { لاتخفى عن المتلقي" (ب0). }
$$

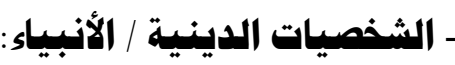

الثخصيات الدينية خاصة شخصيات الأنبياء (عليهم السلام) تُعدُّ مصدراً مهمّاً من الانداء المصادر الثرية التي استفاد منها الثعراء المعاصرون في نتاجاتهم، في مدّ تجاربهم الثعرية بنسخ الحياة، وإعطائها صفة الديمومة والبقاء، وإكسابها قوّة وفاعلية، وذلك لما

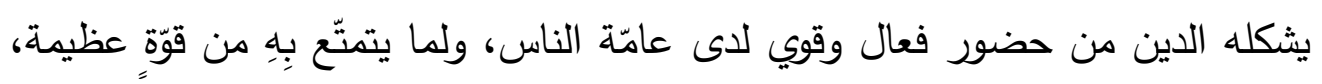

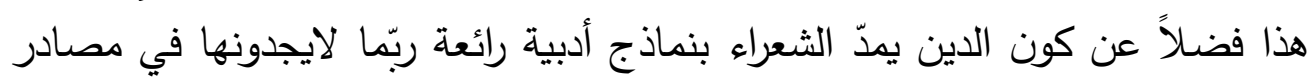

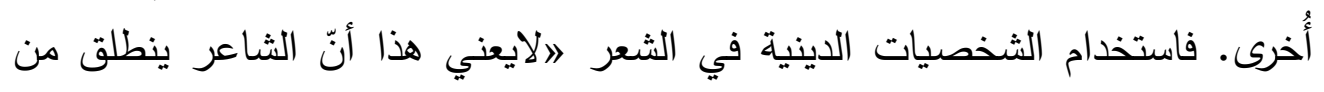

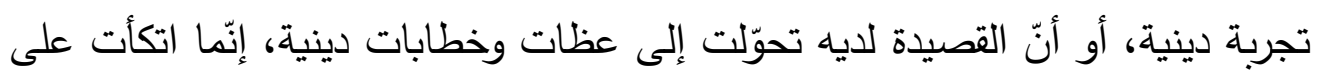
ذلك وأفادت منه بدلالاته المختلفة، لتقوم القصيدة على هذه العناصر مع رؤية الثاعر وواقعه، مشكلّةً حركيتها ووجودها وحياتها الخاصة والعمل على صهر هذه هذه الرموز ضمن حس وإع يتوسّد الرؤيا الإستشرافية والإستيعاب النقدي للماضي، لإنتاج نصٍّ

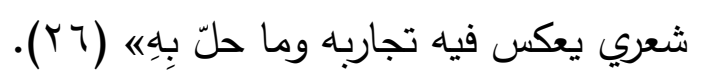

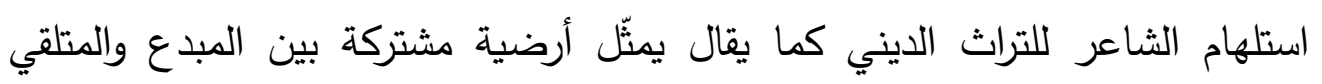
ويساعده في تقوية المعنى الذي يريد التعبير عنه، ويساعده في إيجاد لغة حيّة مع

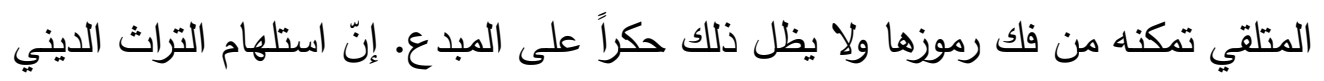
يعزّ ثقة المتلقي بالثاعر ويدخله في حوار حضاري معه بغية فهم الحاضر وكثف إنف

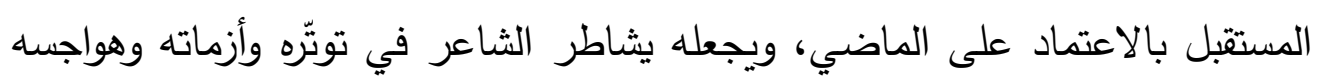
وربما اسقاطاته الذاتية، وبذلك يلج الثاعر إلى ذوات الآخرين، وينقل وعيه إليهم

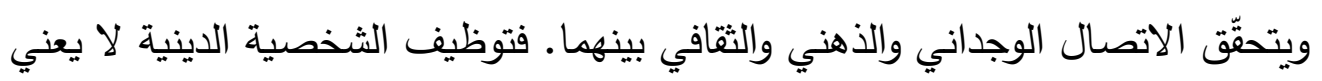
تقديمها للمتلقي بصورة سطحية وتقريرية مباشرة، بل يعني صياغتها بطريقة جديدة

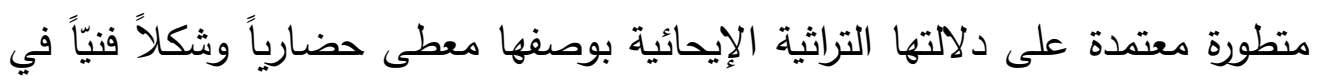
بناء العملية الشعرية، إذ تعكس الشخصيات الدينية المستدعاة أبعاداً اجتماعية ودينية 


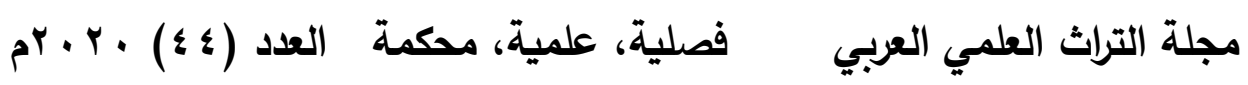

وسياسية وفكرية في العصر الحاضر، ممّا يتيح التواصل بين الماضي والحاضر، وفي هذه الحالة ييرز دور المتلقي الذي يكثف بوعيه عن قيمة ذلك التواصل، وأثره في

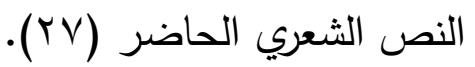

هذه الثخصيات الدينية وأبعادها الرمزية "حظيت بأهمية بالغة لاى الكثير من الثعراء

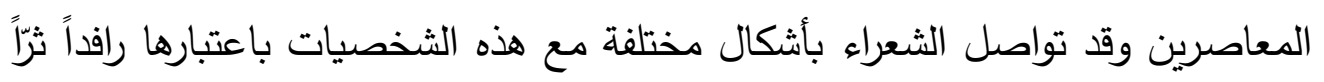

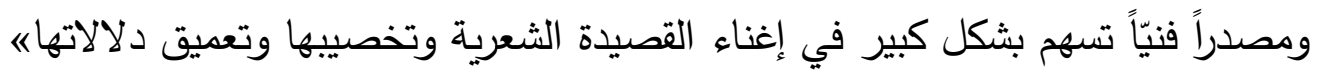
(Y^) (الثاعر يونس البوسعيدي عكف على توظيف شخصيات الأنبياء في شعره،

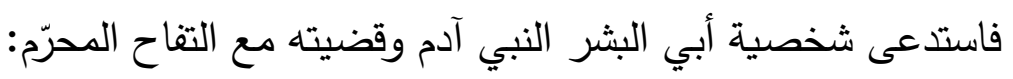

آدَمُ ذاقَهُهُ، وغُغُرِمَ خمرَه

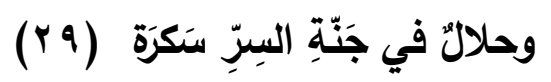

وجَنَيتُ التفاحَ، إنّ أبانا

إغتَفْر لي إذا اشتهيتُك سُكراً

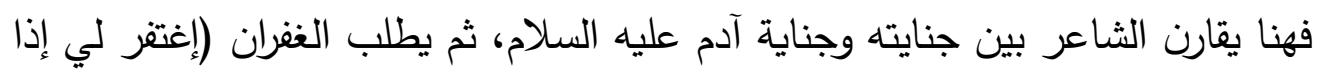

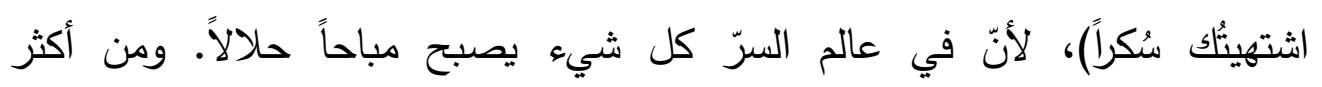

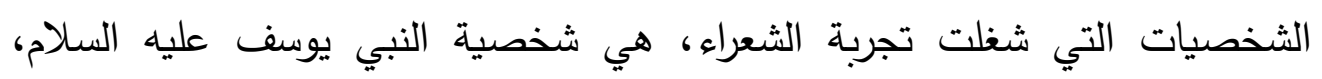

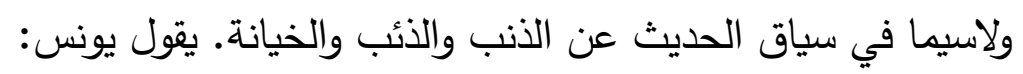

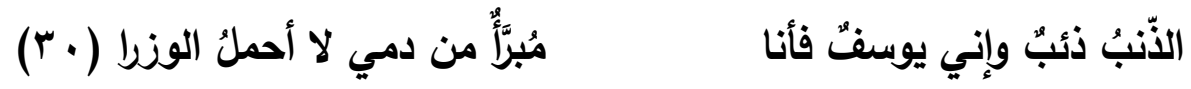

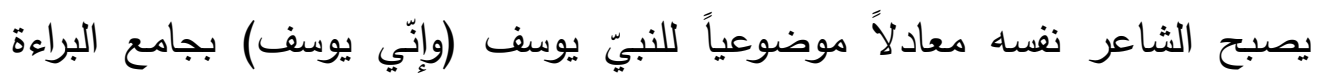

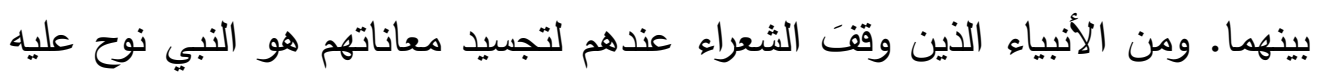

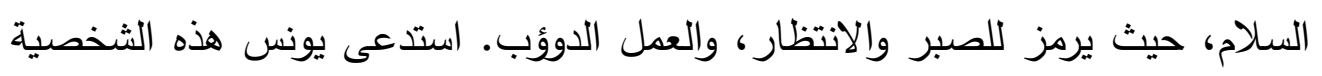
الاينية في شعره قائلاً:

وقد سترثُ بِِ طريَّ قروحي

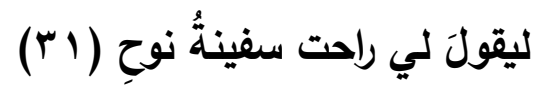

وسجى المساءُ كطرُةٍٍ بعباءتي

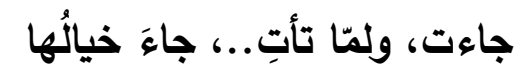

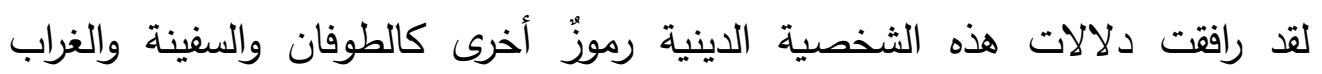
للارتباط الدلالي والزمني. وقد أدرك الثاعر البوسعيدي هذه العلاقة فأضاف (سفنية)

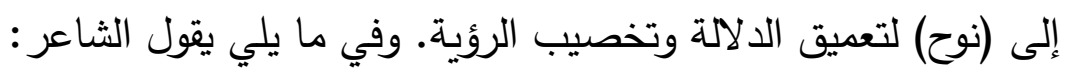




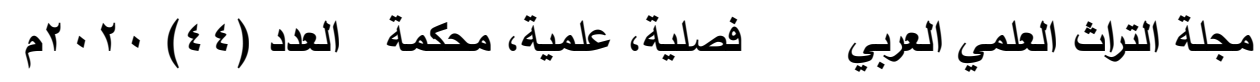

مانَ...، وهذي الأملاك طوعُ يديّه

خَدَمي خُشَّعُ، كجنِّ سُلي

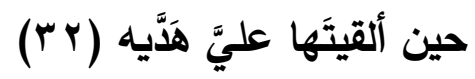

والنواميسُ مثلُ ألواح موسى لئل

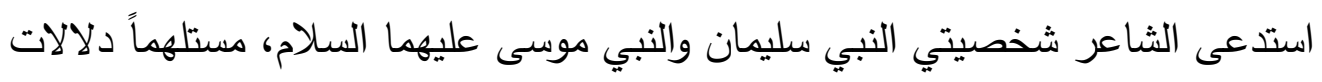

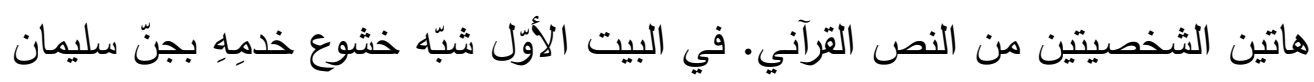

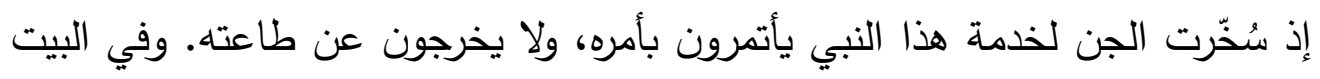

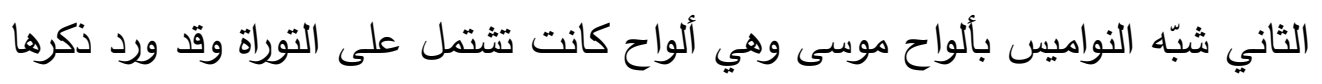

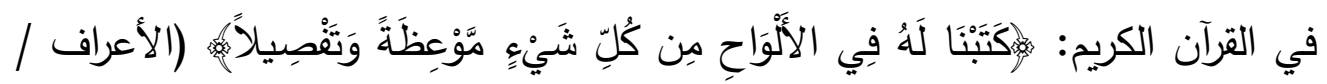
ـ ( ). وفي البيت الآتي جاء استدعى النبي موسى أيضاً:

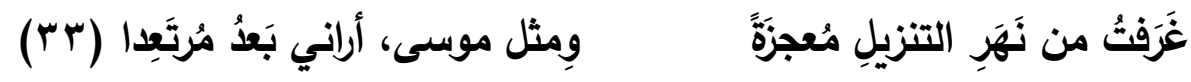

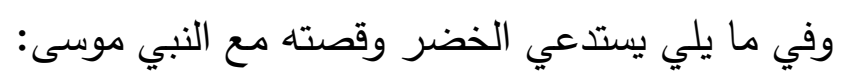

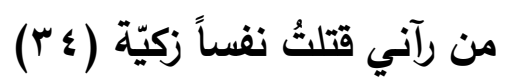

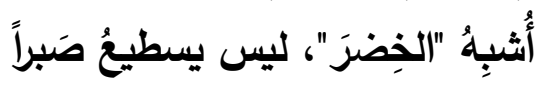

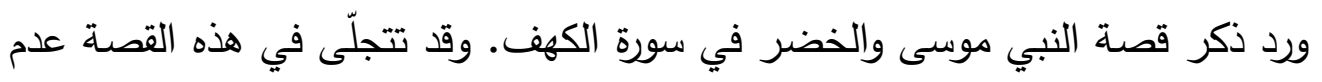

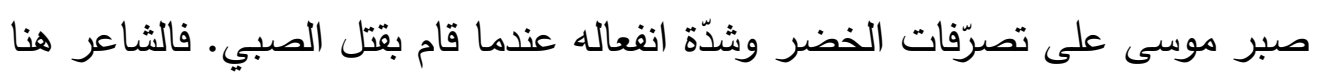
يثبّه نفسه بالخضر إذ يرى لا صبرَ لمن يرافقه ويرى تصرفاته.

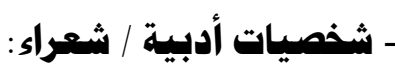

في البحث والتقصّي في مجموعة "روحُهُ البحرُ والرّيح" للثاعر العماني يونس

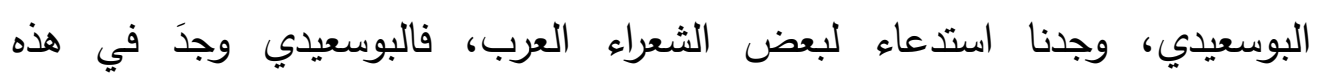

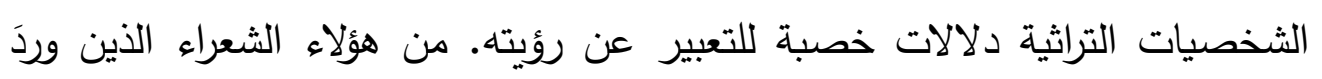

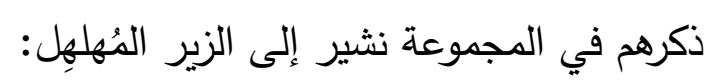

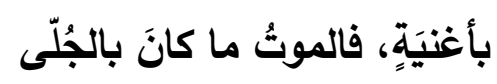

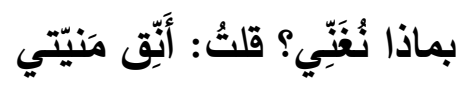

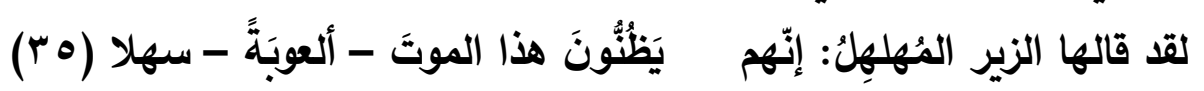

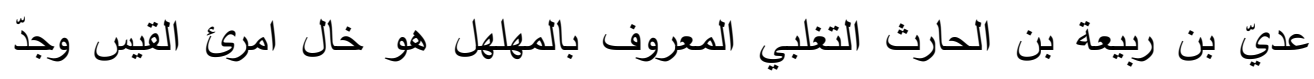

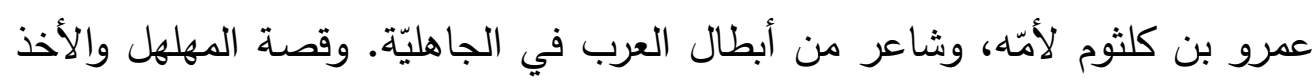
بثأر أخيه كليب معروفة؛ فعندما طعن جساسُ كُليباً بالرمح، وقبل أن يلفظ كليب أنفاسه النها 


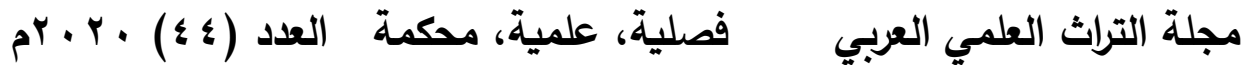

كتب على صخرة بذمه "لا تصالح" وهي رسالة إلى أخيه الزير سالم، وحين وصل الخبر إلى الزير أقسم بأنه سيقتل كل قبيلة بني بكر ، فاشتعلت الحرب التي اشتهرت بالبسوس، وقد استمرت لعشرات السنوات بهدف إبادة البكريين (דب). فكانت ثيمة الكوت التي أثار إليها الثناعر ترافق هذه القصة وشعار "لا تصالح".

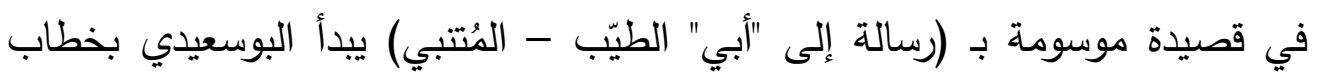
المتنبي قائلاً:

أحبُهُ كنبيّة، أو شبيهِ نَبي

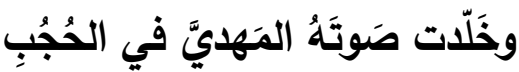

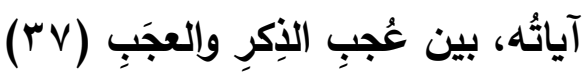

أبي، وأعظِّم بِمَن ناديُتُهُ بأبي

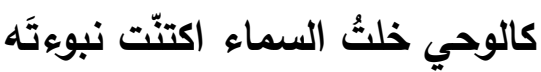

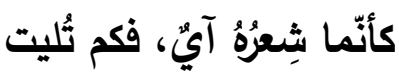
يخاطب المتنبي بـ (أبي) مفتخراً به وبنبوءته في الشعر ، لأنّ المتنبي الإنان شاعراً مفلقاً

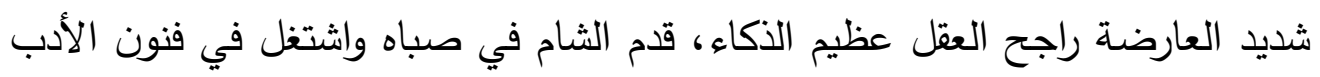

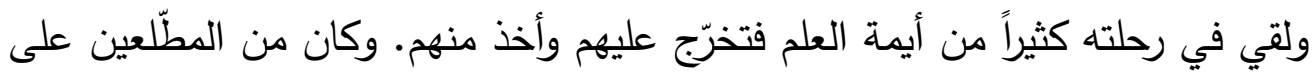

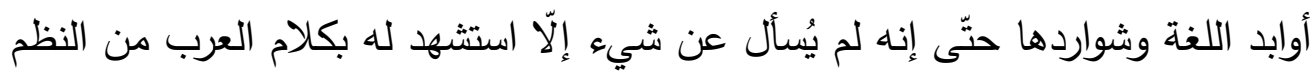

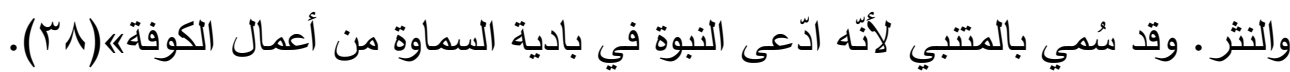

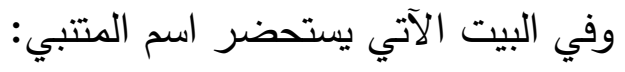

ضلعاءَ، دبّجها بالهلوساتِ غبي (ب9) ألوذُ بالمُتنبّي، أبيٌّ قافيةٍ

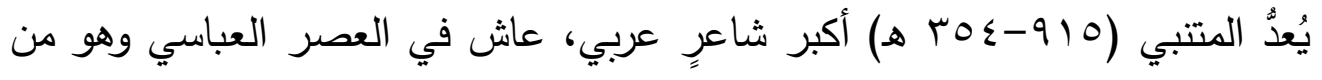

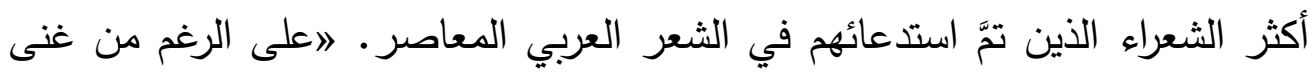

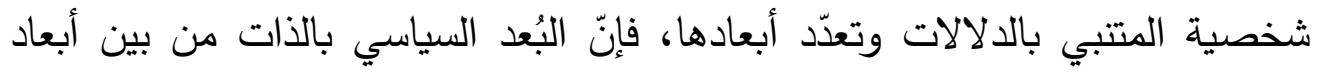

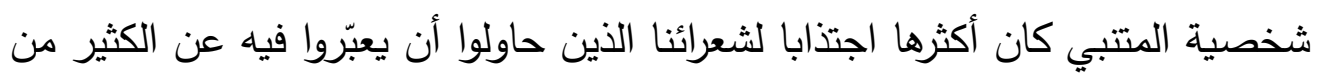
الجوانب السياسية في تجربة الثاعر المعاصر ه (• ع).

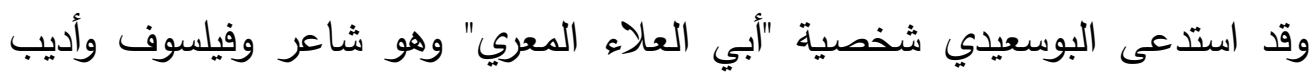

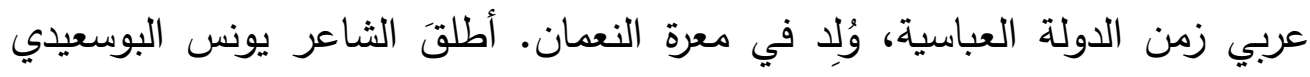




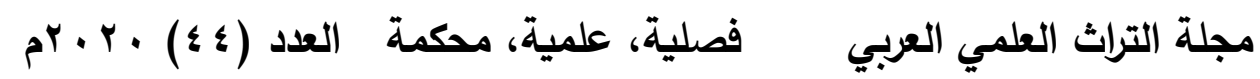

على إحدى قصائد ديوانه هذا العنوان "ربما، هينمة للمعرّي" وفي هذه القصيدة تحدّث

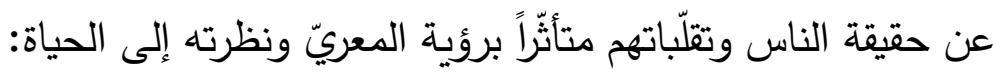

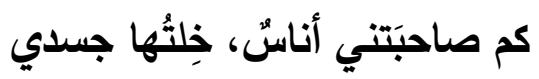

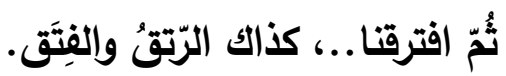

واليومَ يرضى "عليك" الناسُ كلُُهُم

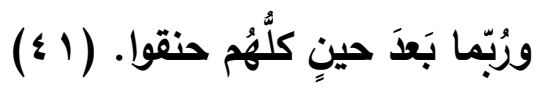

للتعبير عن رؤيته الفلسفية، استدعى شخصية "المعري" التي توافق رؤيته المضطربة والمتشائمة في إصلاح الناس. فمن الشعراء الذين عُرِفوا بنزعتهم التثاؤمية هو أبو لطوئه

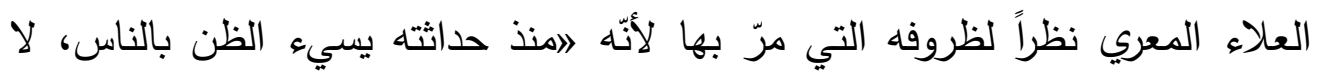

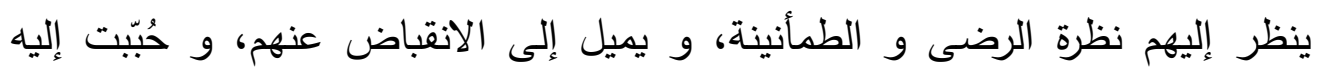
العزلةه (

ومن الثعراء الذين استحضرهم البوسعيدي في ديوانه هو أبو فراس الحمداني ابن عم سيف الدولة. وقد أسر في إحدى المعارك مع الروم. وقد ترك الأسر أثراً ملحوظاً في شعره، إذ رقّ وزاد فيه الحزن والنوح والأسى. يستحضره البوسعيدي في قصيدة موسومة

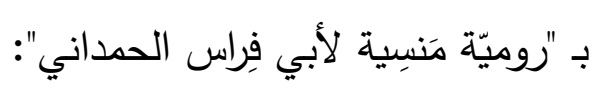

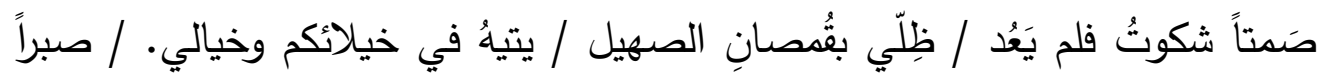

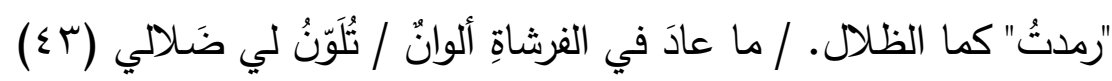
ففي سياق الثكوى استدعى الثاعر هذه الثخصية ليعبّر عن اسقاطات نفسه

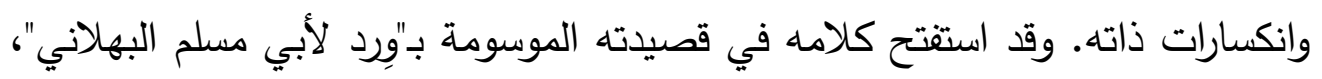
بحروف مقطعة على سياق النص القرآني:

بـ "طها" بذّلّي باحتقاري وبالتَوبِ

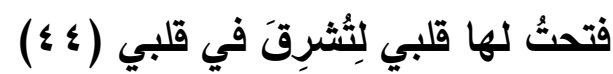

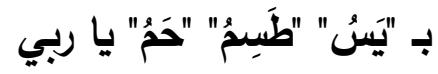

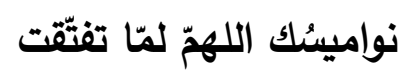

والبهلاني شاعر عماني تقرّد بصوته النهضوي في عصره وقد حمل مشاعل العلم والاهتداء، ومنارات الفكر والاقتداء. وُلد في مدينة وادي محرم في سلطنة عمان 


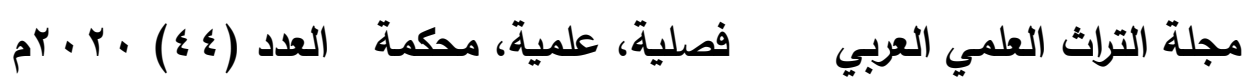

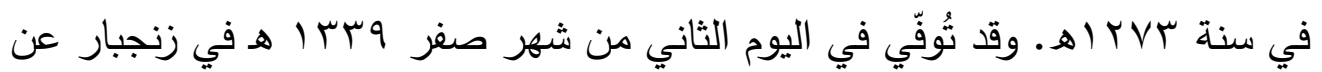

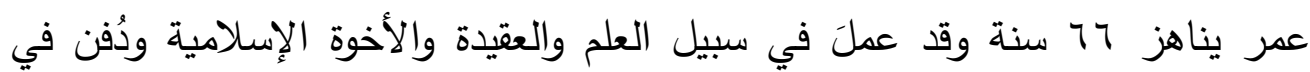
مدينة زنجبار في شرق أفريقيا. - الشخصيات التاريخية

إنّ العلاقة بين الثعر والتاريخ وطيدةُ، والثعر العربي المعاصر له حظٌ وافرُّ

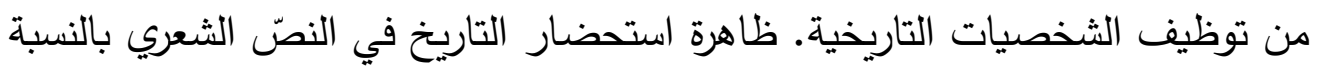

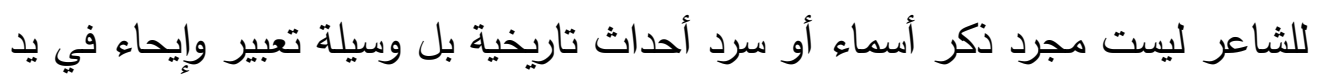
الثاعر يعبّر بها عن رؤيته المعاصرة، فالثاعر المعاصر عندما يستحضر المادّة

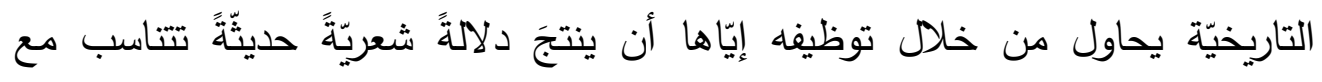
أوضاع العصر الراهن. والثاعر يونس البوسعيدي لم يغفل المادّة التاريخيّة في شعره.

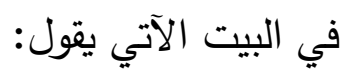

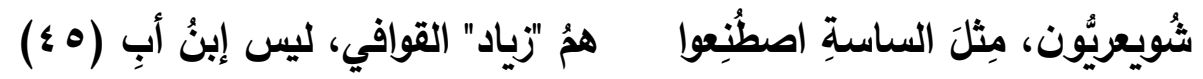

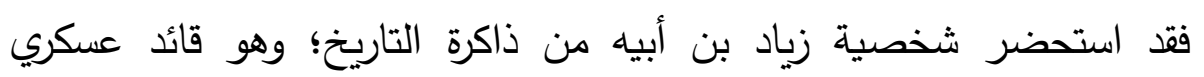

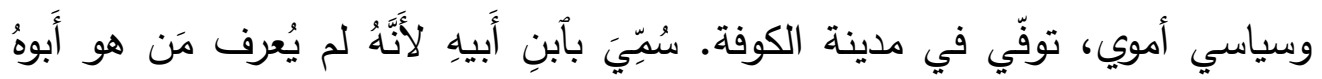

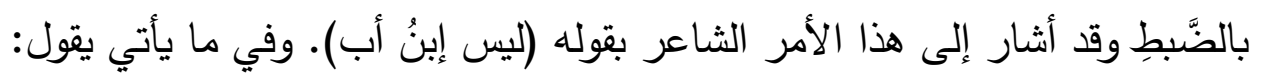

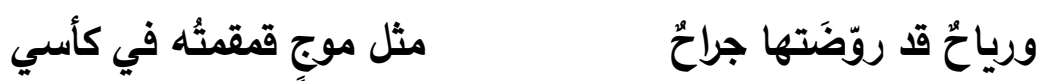

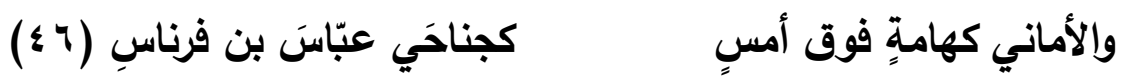

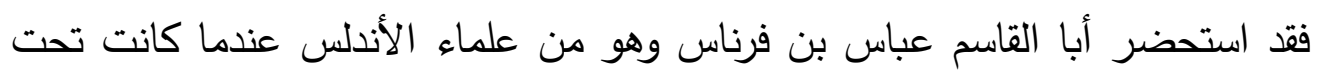

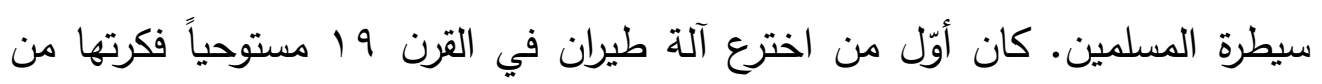

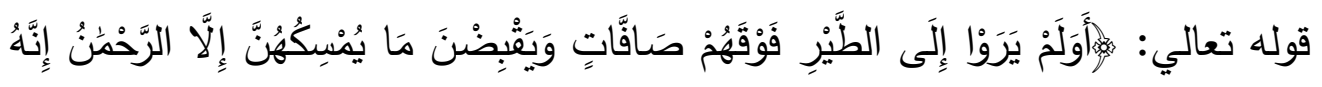

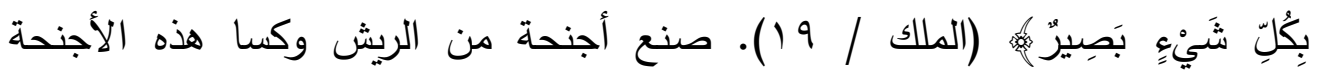
بالحرير وقد استدعى شخصية الجنيد البغدادي من ذاكرة التاريخ: وآهِ، طال على الأبوابِ موقفُعُ

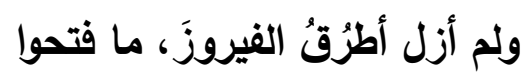




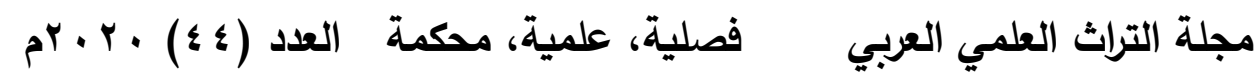

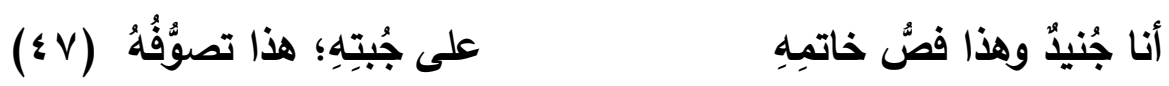

استحضر الإمام العارف الجنيد بن محم وأصله من نهاوند في هدان، ومولده ونشأته

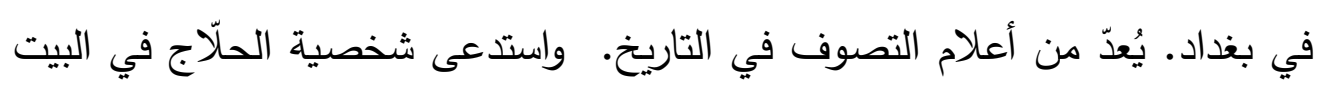

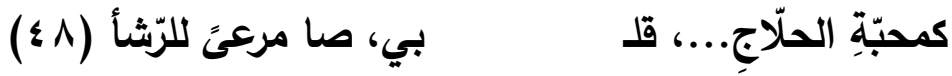

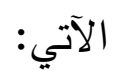

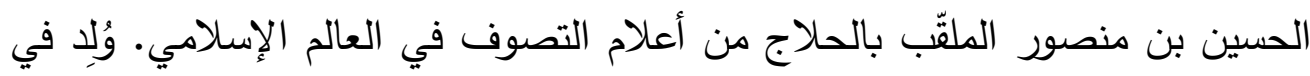

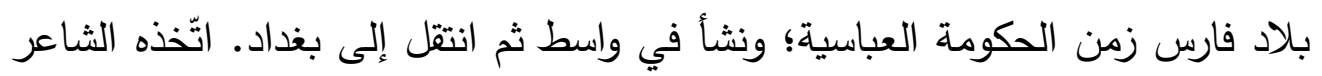

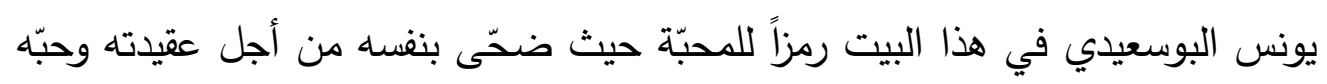

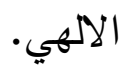

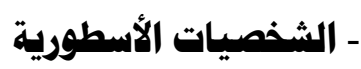

عندما يعود الثاعر المعاصر إلى الأساطير فإنّه لا يعود إلى تلك الأحداث والجزئيات

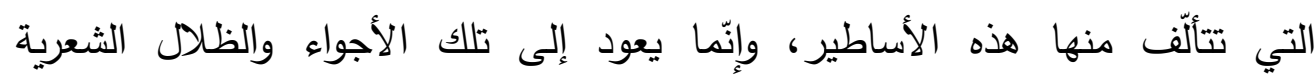

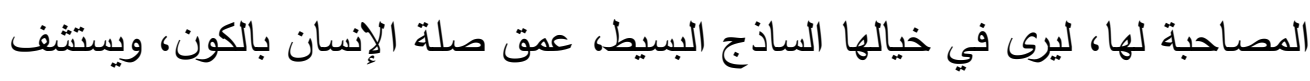

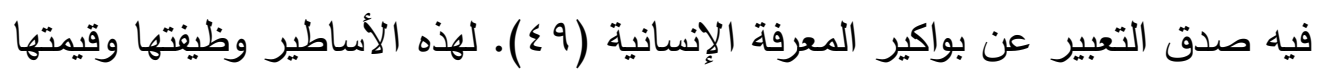

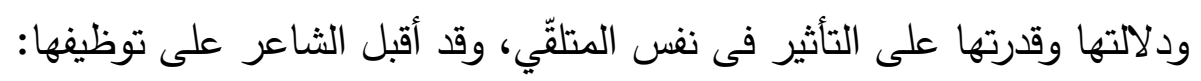
سبعونَ مغفرةً في نصف معصطة

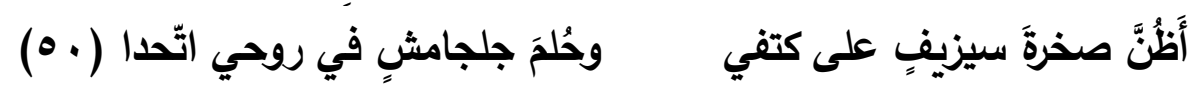

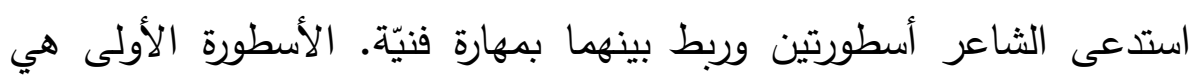

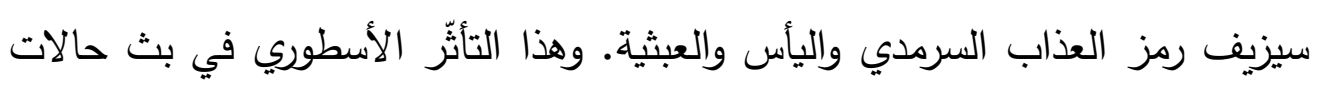

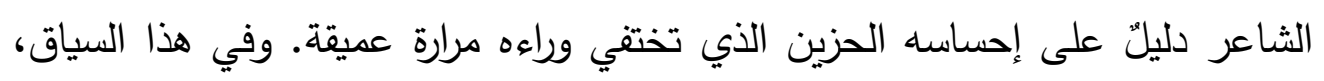

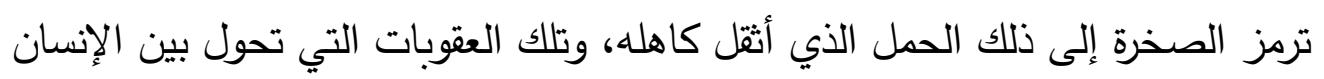

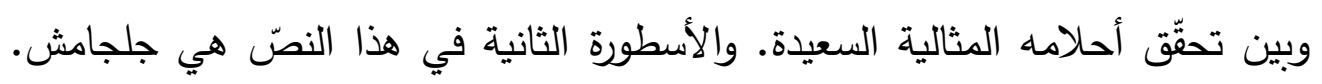

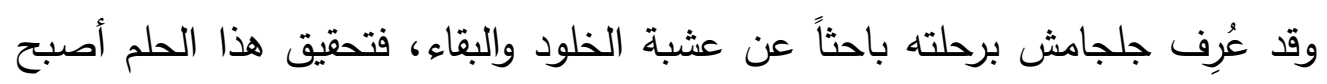
هاجسه الأوّل والأخير • وقد وجد الثاعر هذا الحُلم متّحداً في روحه. 


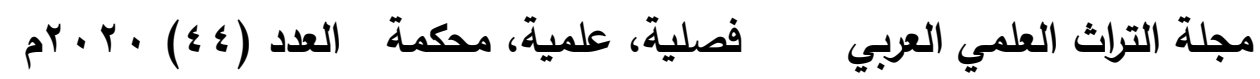

وفي المقبوس الآتي استحضر البوسعيدي أسطورة أخرى:

لقد طفحَ الحلمُ والماءُ أعمى ألمى

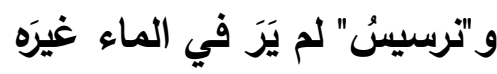

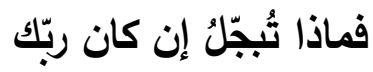

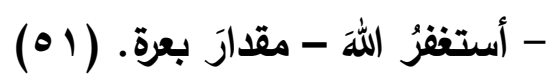

ترتكز أسطورة نرسيس على ثيمة الغرور التي أصبحت سمة بارزة لها إذ بدأ نرسيس

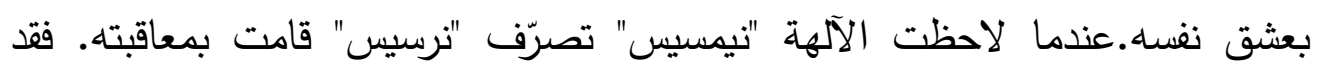

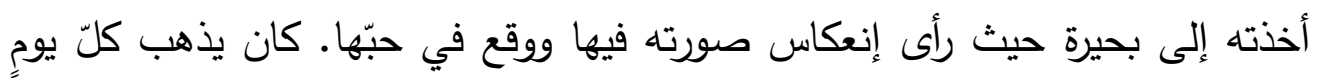

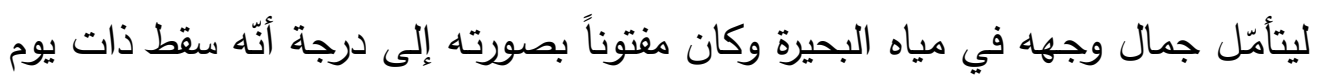

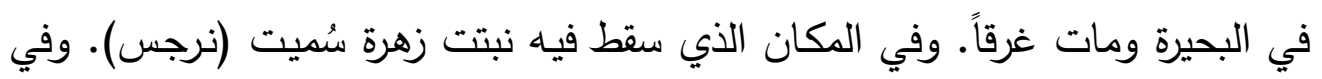

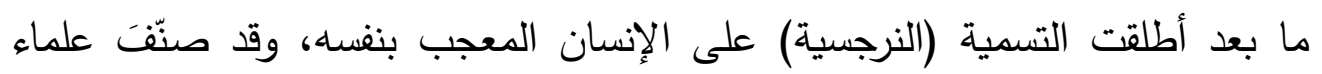
النفس هذا الإعجاب ضمن الأمراض النفسيّة (ror).

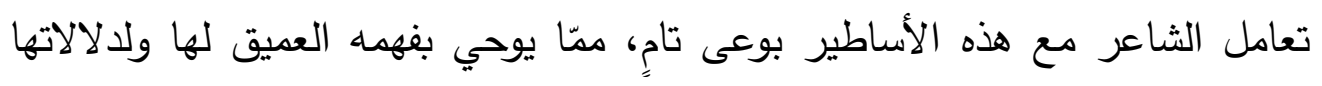
الخصبة وقد استخدمها استخداماً فنيّاً. ب) المثاقفة الخارجية الثناعر العماني المعاصر يونس البوسعيدي لم يحدّد نفسه بالمثاقفة الداخليّة في تركيزه

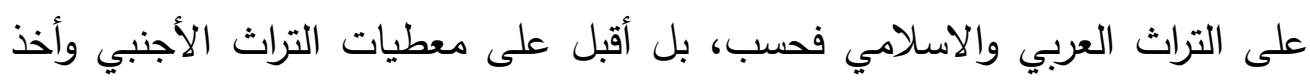

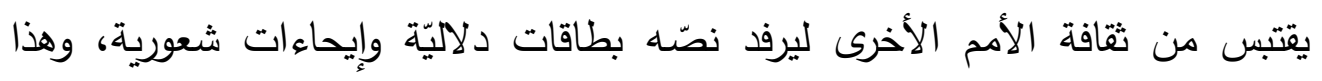

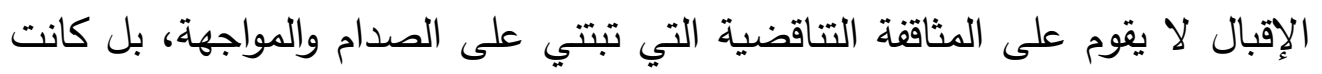
هذه حركة مبنيّة على التقارب، والاحتكاك، والتمازج، والتبادل.

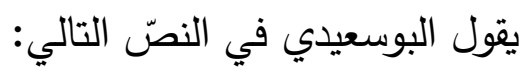

وطنّ، وإن ظنّوا تناءى وإبتَعد

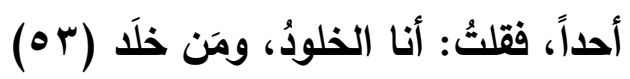

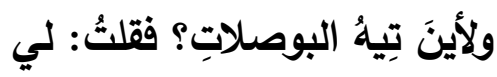

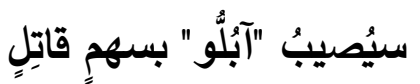




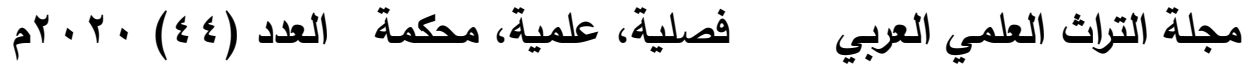

وقد جاء في هامش الصفحة تعقيباً على هذه اللفظة ضآبُلُّ : بالنطق الإنجليزي، أو أبولّو

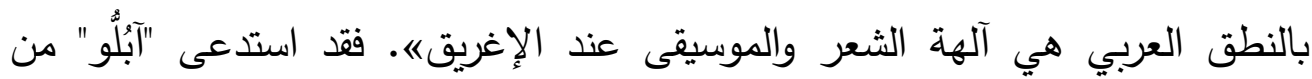

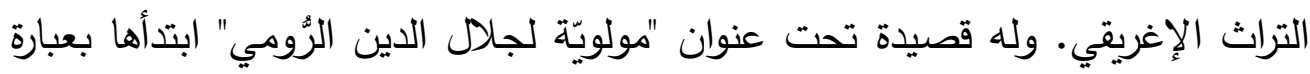

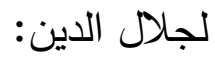

"إنكك قد رأيتَ الصورةَ، ولكنك غفلتَ عن المعنى《

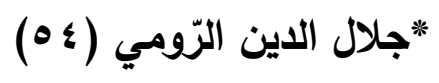

جلال الدين الرومي شاعر وعالم صوفي فارسي، يُدُُّ من أبرز أعلام التصوّف الفلسفي

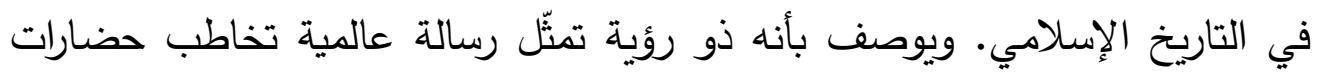
العالم كافة باعتبارها مصدر إلهام لكل الناس. وفي هذه القصيدة مناشدات عرفانية يخاطب فيها الثاعر الذات الألهيّة، وقد وجد في شخصيّة الترّومي دلالة خصبة للتعبير

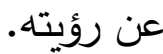

وفي قصيدة موسومة بـ "تبتُّلات إلى السيمرغ" يقول البوسعيدي:

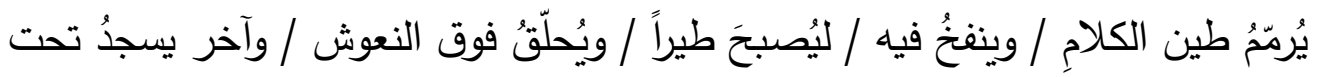

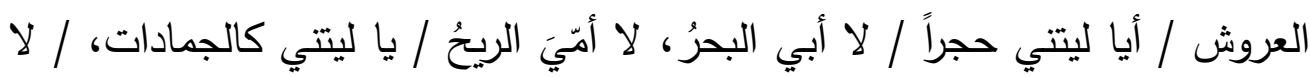
أشتكي: / مسّني الثِعرُ ـ (00) السيمرغ هو طير خرافيّ يكثر ذكره في الأساطير الفارسية وهو يعادل العنقاء في

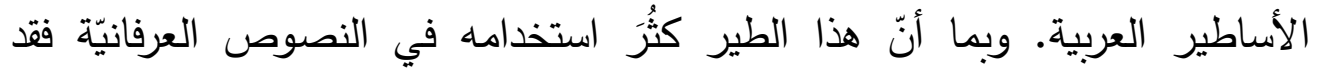

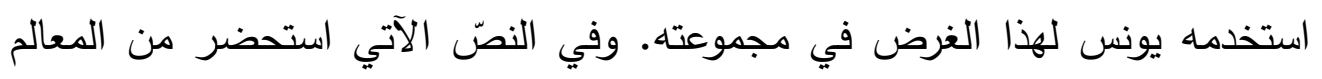
الفارسية منطقة "شعب بوّان":

غريبة السجعِ، قالت إنـهُ عربي

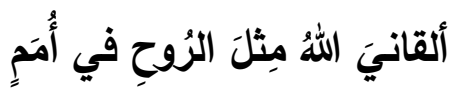

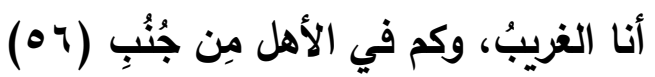
كأنّها شِعبُ بوَّانٍ، وأحسَبْني وشِعب بَوَان هو من المتتزهات الجميلة، كثير الشجر والمياه، يقع في بلاد فارس في الطريق إلى شيراز، وذكره المتنبي في شعره. وقد ذكر الثاعر يونس 


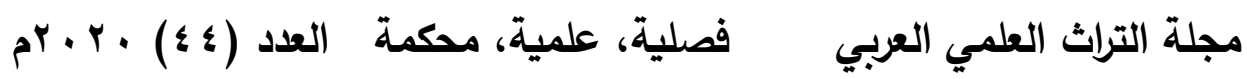

البوسعيدي هذا المكان ليجسّد غربته كما كان المتنبي غربباً في هذا الثعب إذ يكون

$$
\text { الفتى العربي فيه غربب الوجه واليد واللسان. }
$$

الخاتمة:

- استوحى الثاعر يونس البوسعيدي من التراث للتعبير عن تميّزه الإبداعي روحياً

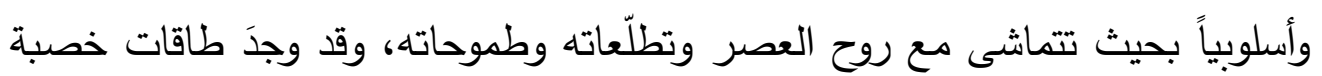

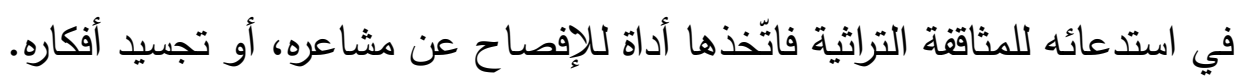
- رشحّنا مجموعة "روحُهُ البحرُ والرّيح" محوراً لهذه الدراسة لتزاحم المعطيات التراثية فيها، فالثاعر للتعبير عن المفاهيم العرفانية وجدَ في هذه المعطيات التراثية طاقة

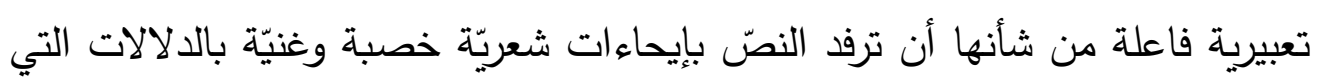
تشير إشارة جلية إلى عميق قراءته لهذا التراث.

- اعتمد البوسعيدي في نصوصه على المثاقفة الداخليّة أكثر من مظاهر المثاقفة الخارجية؛ ففي الداخلية ركّز في النص القرآني ثم على النصوص الثعرية قديماً وحديثاً، ولم يغفل الثخصيات الدينيّة ولاسيما الأنبياء كالنبي موسى وخضر فلئ علئ عليهما السلام، والشخصيات الأدبية كالمتنبي. - أمّا المثاقفة الخارجية فقد ركّز في مفاهيم لا تتنمي إلى الثقافة العربية منها "آبولو" آلهة الثعر والموسيقى عند الإغريق، وقد استحضر شخصيات عرفانية منها الثاعر الفارسي جلال الدين الرّومي. ومن التراث الفارسي استخدم "السيمرغ (يعادل العنقاء في التراث العربي) وشِعب بوّان (منطقة خلّابة قريبة من شيراز).

\section{Conclusion}

-Yones Alboosaeedi used tradition to express his distinctiveness stylistically and spiritually in a way that is moving with the time and its hopes and inspirations. He found great powers in using acculturation so he applied it to express his feelings and thoughts.

-We chose his book" his soul is the sea and the wind" as an axis to this study to compete the traditional facts and data. The poet found that by 


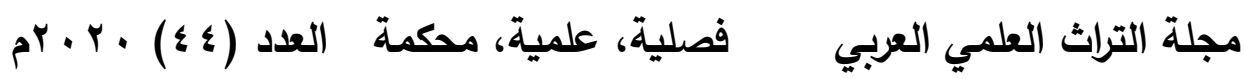

using tradition, he could express mystic concepts that help the text to be full of great inspirations and signs that tell us the poet has read the tradition well.

-The poet relied on inner acculturation more the outer acculturation. In the first he focused on the quranic texts and on the old and modern texts. He never forgets the religious characters especially prophets as "Moses" and "Khedr" and others as "Almotanabi".

-In the second one he focused on concepts which are not related to arabic culture as the goddess "Appolo" and he summoned up mystic characters as the Iranian poet Jalal Aldin Alroomi and "Simorq" and "Bawan side" near Shiraz in Iran.

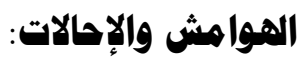

1- جميل نجيب التلاوي: المثاقفة؛ عبدالصبور وإليوت ... دراسة عبر حضارية، ترجمة ماهر مهدي

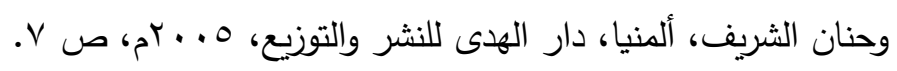

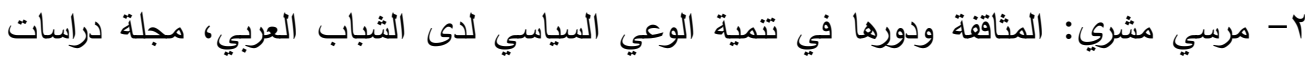

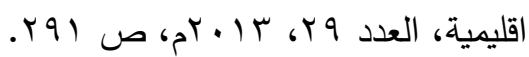

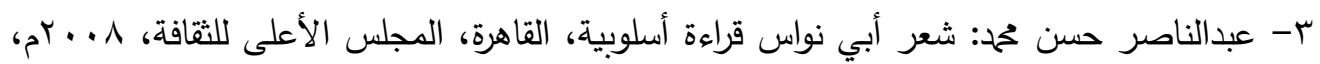
ص שV IV

ع- رواء نعاس محح: 》المثاقفة والمثاقفة النقدية (في الفكر النقدي العربي)ه، مجلة القادسية في الآداب

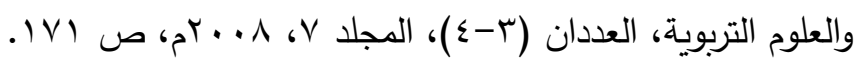

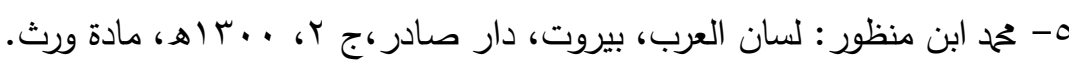

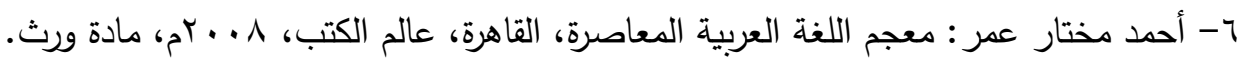
V- رسول بلاوي: 》توظيف شخصيات التراث الديني في شعر أديب كمال الدينه، مجلة التراث

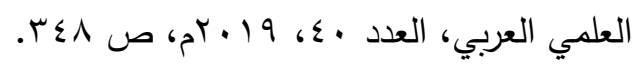

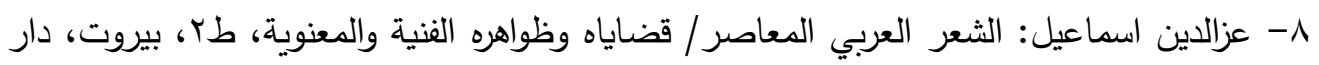

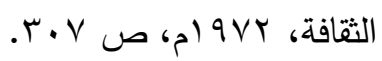

9- على عشري زايد: استدعاء الثخصيات التراثية في الشعر العربي المعاصر، طرابلس، الثركة

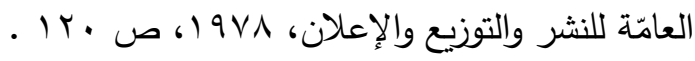




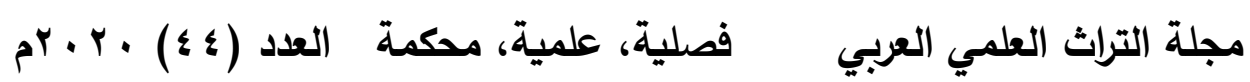

• 1- رسول بلاوي: 》استدعاء التراث في شعر عبدالسادة البصريه،، مجلة تراث البصرة، السنة ب،

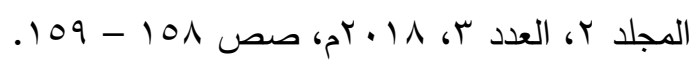

11- عزالدين اسماعيل: الثعر العربي المعاصر/ قضاياه وظواهره الفنية والمعنوية، ص بس. r ا- يونس البوسعيدي: روحُهُ البحرُ والرّبح، مسقط، بيت الغشام للنشر والترجمة بالاشترك مع

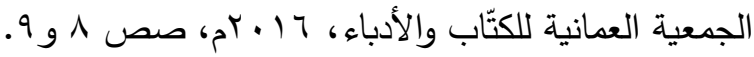

$$
\begin{aligned}
& \text { r I - المصدر السابق، ص VV } \\
& \text { ع ا- المصدر السابق، ص اب . . } \\
& \text { 1 } 1 \text { - المصدر السابق، ص r بr . } \\
& \text { ד ו - المصدر السابق، ص זr . } \\
& \text { IV - المصدر السابق، ص ا ا. }
\end{aligned}
$$

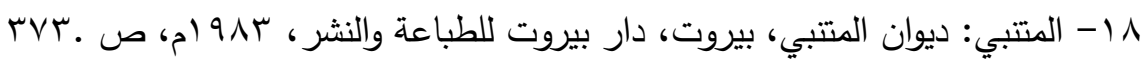

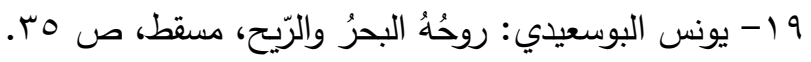

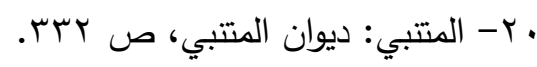

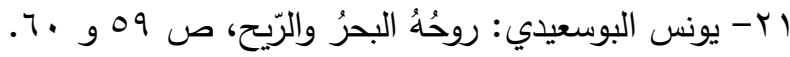
r ب- أبو عبادة البحتري: ديوان البحتري، تحقيق وتعليق عمر فاروق الطباع، بيروت، دار الأرقم،

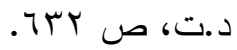

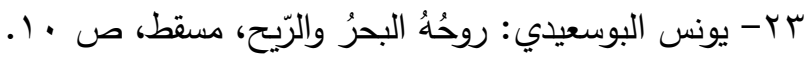
ع ז- رسول بلاوي، وتوفيق رضايور محيسني: 》استدعاء التراث التاريخي في شعر جواد الحطّابه،

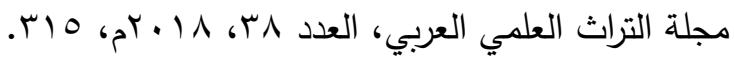
هץ- رسول بلاوي، وآخرون: 》موتيف استدعاء الشخصيات التراثية في شعر يحيى السماويه، مجلة

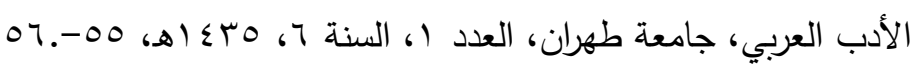

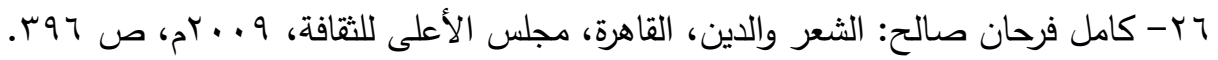
V V - عاطي عبيات، ورسول بلاوي: „الثخصية القرآنية عند شعراء الثتات الفلسطينيين (أنموذجاً

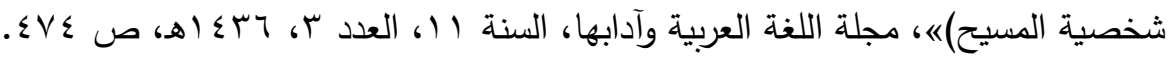
^ץ- حسين لفته حافظ، ورسول بلاوي: 》إستدعاء شخصيّة الإمام الحسين وفاعليتها الرمزيّة في شعر

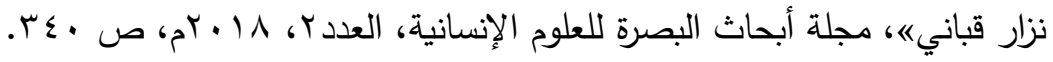
و - يونس البوسعيدي: روحُهُ البحرُ والرّّح، ص 9 ا ـ

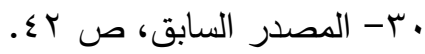




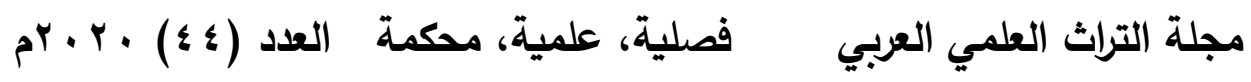

$$
\begin{aligned}
& \text { ا ו- الدصدر السابق، ص NV. }
\end{aligned}
$$

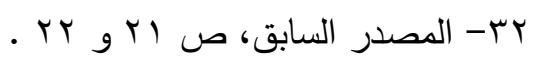

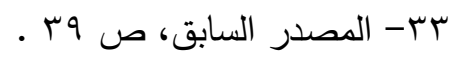

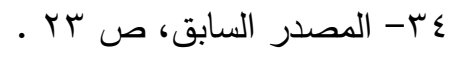

$$
\begin{aligned}
& \text { هץ- المصدر السابق، ص 9 ؟ـ. }
\end{aligned}
$$

بr- منال شوابح: موازنة بين بكائيات المهلهل بن بيعة والخنساء / دراسة فنية موضوعية، رسالة

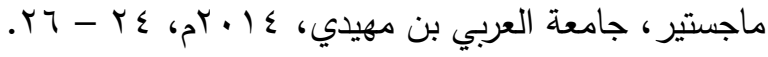

$$
\begin{aligned}
& \text { גץ }
\end{aligned}
$$

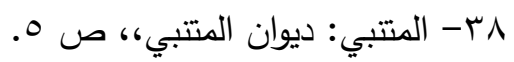

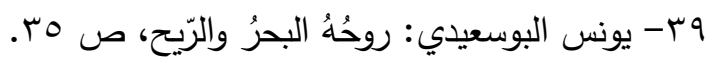

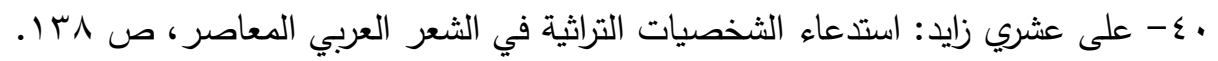

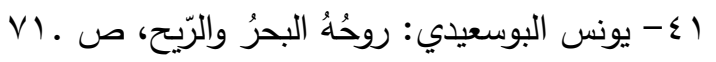

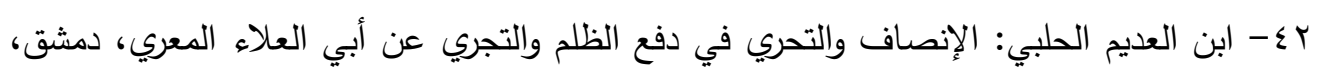

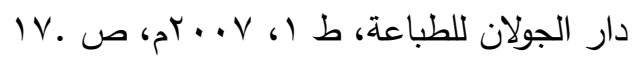

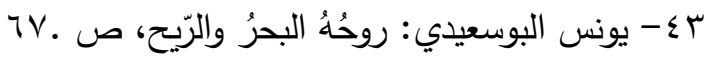

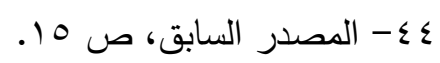

0ء- المصدر السابق، ص بـ ـ

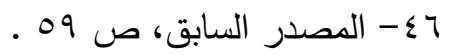

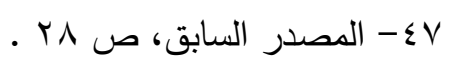

A乏 - المصدر السابق، ص سז .

9 - كاملي بلحاج: أثر التراث الثعبي في تشكيل القصيدة العربية المعاصرة (قراءة في المكونات

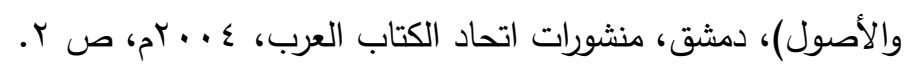

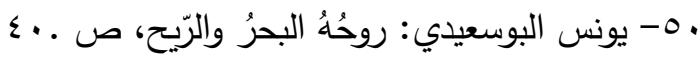

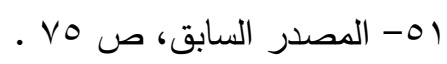

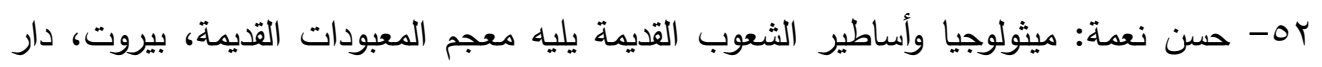

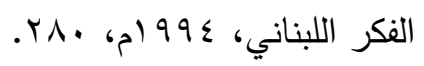

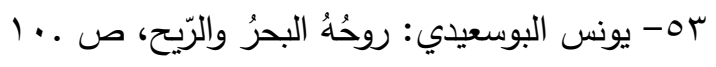

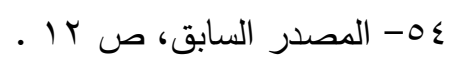




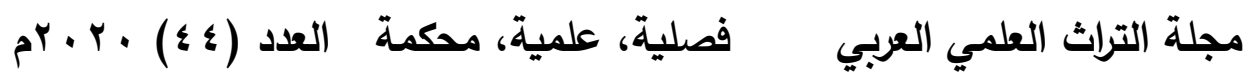

$$
\begin{aligned}
& \text { 00- المصدر السابق، ص •r . }
\end{aligned}
$$

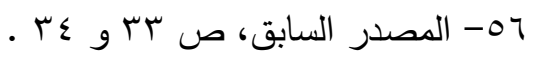

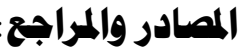

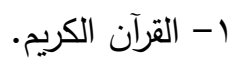

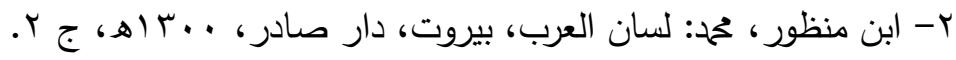

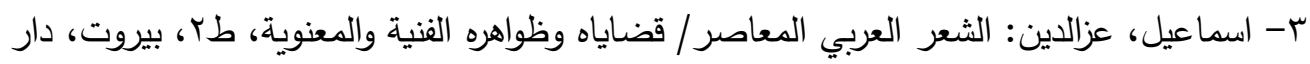

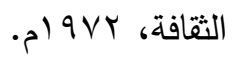

ع- البحتري، أبو عبادة: ديوان البحتري، تحقيق وتعليق عمر فاروق الطباع، بيروت، دار الأرقم،

$$
\text { د.ت }
$$

ه- بلاوي، رسول: 》استدعاء التراث في شعر عبدالسادة البصري《، مجلة تراث البصرة، السنة r،

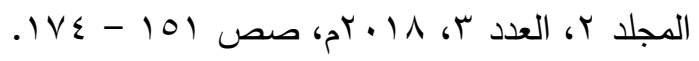

1-----------: اتوظيف شخصيات التراث الديني في شعر أديب كمال الدينه، مجلة التراث

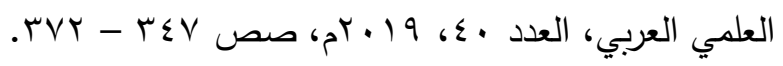

V- بلاوي، رسول وآخرون: الموتيف استدعاء الثخصيات التراثية في شعر يحيى السماويه،، مجلة

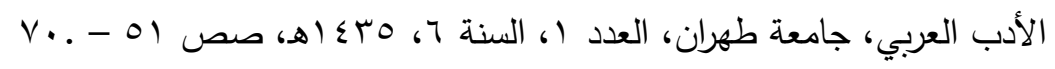

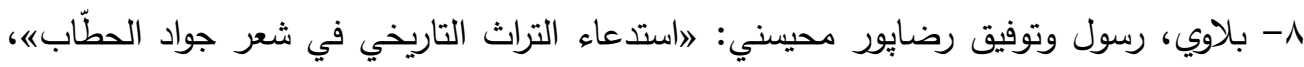

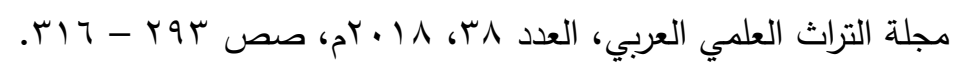

9- بلحاج، كاملي: أثر التراث الثعبي في تثكيل القصيدة العربية المعاصرة (قراءة في المكونات

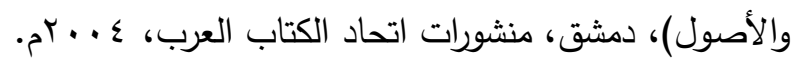

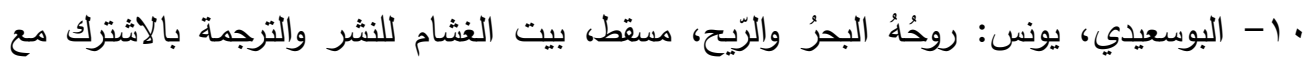

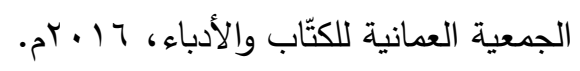

1) التلاوي، جميل نجيب: المثاقفة؛ عبدالصبور وإليوت ... دراسة عبر حضارية، ترجمة ماهر

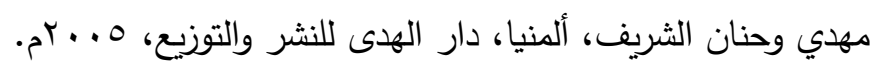

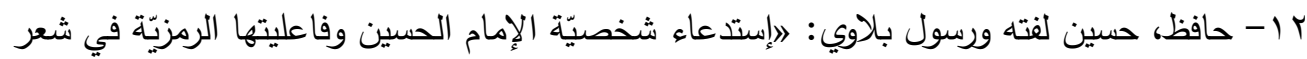

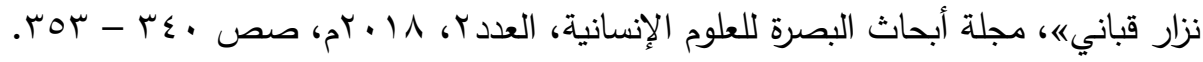

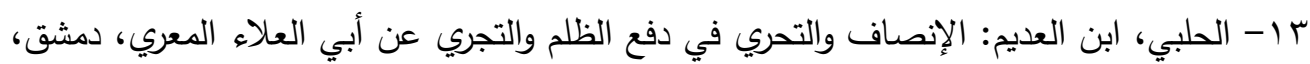

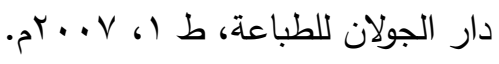




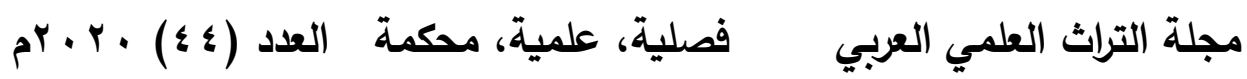

ع ا - شوابح، منال: موازنة بين بكائيات المهلهل بن بيعة والخنساء / دراسة فنية موضوعية، رسالة

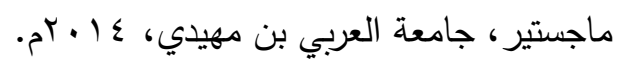

1 ا- صالح، كامل فرحان: الثعر والدين، القاهرة، مجلس الأعلى للثقافة، 9 . . بـم.

7 ا - عبيات، عاطي ورسول بلاوي: 》الثخصية القرآنية عند شعراء الثتات الفلسطينيين (أنموذجاً

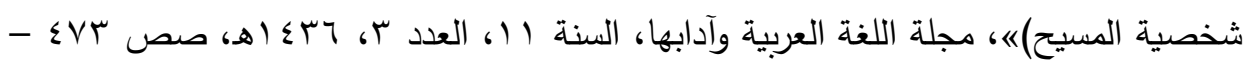

IV

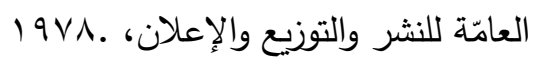

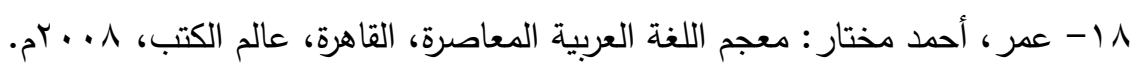

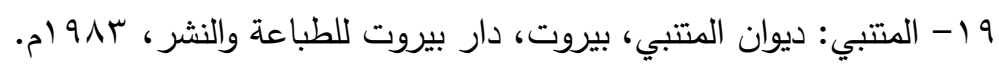

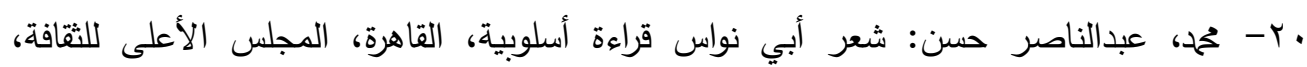

$$
\text { . . . }
$$

اץ- مشري، مرسي: المثاقفة ودورها في تتمية الوعي السياسي لدى الثباب العربي، مجلة دراسات

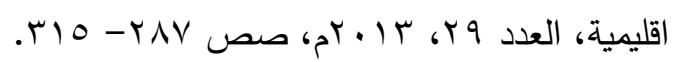

ץY- نعاس ححم، رواء: 》المثاقفة والمثاقفة النقدية (في الفكر النقدي العربي)ه، مجلة القادسية في

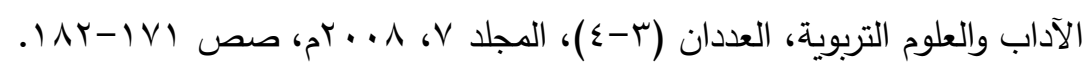

بr- نعمة، حسن: ميثولوجيا وأساطير الثعوب القديمة يليه معجم المعبودات القديمة، بيروت، دار

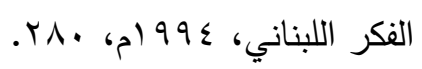

\section{List of Sources and reference:}

I- The Holy Quran.

II- Ibn Manzoor, Muhammad: Lisan Al-Arab, Beirut,Dar Sader, 1300, Part 2. III- Ismail, Ezz El-Din: Contemporary Arab Poetry / Its Issues and its

Technical and Moral Phenomena, 2nd edition, Beirut, Dar Al-Thaqafa, 1972.

IV- Al-Bahtari, Abu Ubada: Diwan al-Bahtari, investigation and commentary by Omar Farouk Al-Tabba, Beirut, Dar Al-Arqam, d. 


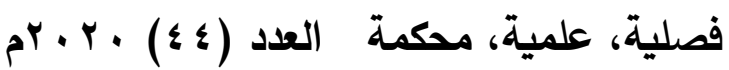

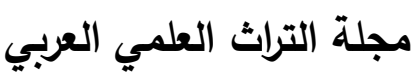

V- Balavi, Rasoul: "Summoning Heritage in the Poetry of Abdel-Sadah Al-

Basry”, Basra Heritage Magazine, Year 2, Volume 2, Issue 3, 2018, pp. $151-174$.

VI ------------: "Invoking religious characters in Adib Kamal Aldin's poerry", Journal of Arab Scientific Heritage, No. 40, 2019, pp. 347-372.

VII- Balavi, Rasoul And others: "Motivating summoning the traditional characters in Yahya al-Samawi poetry", Journal of Arabic Literature, University of Tehran, No. 1, Year 6, 1435, pp. 51-70.

VIII- Balavi, Rasoul and Tawfiq Razapur Muhaisni: "Recalling Historical Heritage in the Poetry of Jawad Al-Hattab", Journal of Arab Scientific Heritage, No. 38, 2018, pp. 293-31.

IX- Belhaj, Kamli: The Impact of Folklore in Shaping the Contemporary Arab Poem (Reading in components and origins), Damascus, Arab Writers Union publications, 2004.

X-Al-Busaidi, Yunus: Its Soul and the Wind, Muscat, House of Al-Ghashm for Publishing and Translation, in cooperation with the Omani Society of Writers and Writers, 2016.

XI- Al-Talawy, Jamil Najeeb: acculturation: Abdel-Sabour and Elliot ... A cross-cultural study, translated by Maher Mahdi and Hanan El-Sharif, Germany, Dar Al-Hadi for Publishing and Distribution, 2005.

XII- Hafez, Hussein Lafta and Rasoul Balavi: "Recalling the Imam Hussein's Character and its Symbolic Effectiveness in the Poetry of Nizar Qabbani", Basra Research Journal of Humanities, No. 2, 2018, pp. 340-353. XIII- Al-Halabi, Ibn Al-Adim: Equity and Investigation in the Advancement of Injustice and Conduct on the authority of Abi Al-Ala, Damascus, Dar Al-Golan Printing, 1st edition, 2007 AD. 


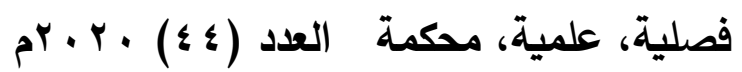

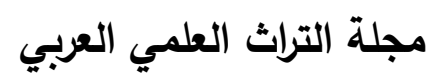

XIV-Shawabeh, Manal: Balancing between the cries of Al-Muhallal bin

Rabia and Al-Khansa / objective technical study, Master Thesis, Al-Arabi bin Mahdi University, 2014.

XV- Saleh, Kamel Farhan: Poetry and Religion, Cairo, The Supreme

Council of Culture, 2009.

XVI- Abiyat, Ati and Rasoul Balavi: "The Qur'anic Personality of the

Palestinian Diaspora Poets (a Model of the Personality of Christ)", Journal of Arabic Language and Literature, Year 11, Issue 3, 1436, pp. 473-491.

XVII-Ashri Zaid, Ali: Recalling the Heritage Persons in Contemporary Arab Poetry, Tripoli, The Public Company for Publishing, Distribution and Advertising, 1978.

XVIII- Omar, Ahmed Mukhtar: A Dictionary of Contemporary Arabic Language, Cairo, Alam Alkotob, 2008.

XIX- Al-Mutanabi: Diwan Al-Mutanabi, Beirut, Beirut House for Printing and Publishing, 1983.

XX- Muhammad, Abdel Nasser Hassan: Poetry of Abu Nawas Stylistic

Reading, Cairo, The Supreme Council of Culture, 2008.

XXI- Mashri, Morsi: acculturation and its role in developing political awareness among Arab youth, Journal of Regional Studies, No. 29, 2013, pp. 287-315.

XXII- Na`as Muhammad, Rawa: "acculturation and Critical acculturation (in Arab Critical Thought)", Al-Qadisiyah Journal in Literature and Educational Sciences, Issues (3-4), Volume 7, 2008 CE, pp. 171-182. XXIV- Neama, Hassan: Mythology and myths of ancient peoples, Attached to the dictionary of ancient deities, Beirut, Dar Alfekr Allobnani, 1994. 